\title{
Article \\ Dexamethasone Inhibits the Pro-Angiogenic Potential of Primary Human Myoblasts
}

\author{
Eva K. Langendorf, Pol M. Rommens (D), Philipp Drees and Ulrike Ritz *(D) \\ Department of Orthopedics and Traumatology, University Medical Center of the Johannes Gutenberg \\ University Mainz, 55131 Mainz, Germany; eva.langendorf@unimedizin-mainz.de (E.K.L.); \\ pol.rommens@unimedizin-mainz.de (P.M.R.); philipp.drees@unimedizin-mainz.de (P.D.) \\ * Correspondence: ritz@uni-mainz.de; Tel.: +49-6131-17-2359 (ext. 55131)
}

Citation: Langendorf, E.K.;

Rommens, P.M.; Drees, P.; Ritz, U.

Dexamethasone Inhibits the

Pro-Angiogenic Potential of Primary Human Myoblasts. Int. J. Mol. Sci. 2021, 22, 7986. https://doi.org/ $10.3390 /$ ijms 22157986

Academic Editor: Anastasios

Lymperopoulos

Received: 22 June 2021

Accepted: 23 July 2021

Published: 26 July 2021

Publisher's Note: MDPI stays neutral with regard to jurisdictional claims in published maps and institutional affiliations.

Copyright: (c) 2021 by the authors. Licensee MDPI, Basel, Switzerland. This article is an open access article distributed under the terms and conditions of the Creative Commons Attribution (CC BY) license (https:// creativecommons.org/licenses/by/ $4.0 /)$.
Abstract: Tissue regeneration depends on the complex processes of angiogenesis, inflammation and wound healing. Regarding muscle tissue, glucocorticoids (GCs) inhibit pro-inflammatory signalling and angiogenesis and lead to muscle atrophy. Our hypothesis is that the synthetic GC dexamethasone (dex) impairs angiogenesis leading to muscle atrophy or inhibited muscle regeneration. Therefore, this study aims to elucidate the effect of dexamethasone on HUVECs under different conditions in mono- and co-culture with myoblasts to evaluate growth behavior and dex impact with regard to muscle atrophy and muscle regeneration. Viability assays, qPCR, immunofluorescence as well as ELISAs were performed on HUVECs, and human primary myoblasts seeded under different culture conditions. Our results show that dex had a higher impact on the tube formation when HUVECs were maintained with VEGF. Gene expression was not influenced by dex and was independent of cells growing in a 2D or 3D matrix. In co-culture CD31 expression was suppressed after incubation with dex and gene expression analysis revealed that dex enhanced expression of myogenic transcription factors, but repressed angiogenic factors. Moreover, dex inhibited the VEGF mediated pro angiogenic effect of myoblasts and inhibited expression of angiogenic inducers in the co-culture model. This is the first study describing a co-culture of human primary myoblast and HUVECs maintained under different conditions. Our results indicate that dex affects angiogenesis via inhibition of VEGF release at least in myoblasts, which could be responsible not only for the development of muscle atrophy after dex administration, but also for inhibition of muscle regeneration after vascular damage.

Keywords: dexamethasone; human primary myoblasts; HUVECs; co-culture; CD31; VEGF

\section{Introduction}

The tightly regulated process of angiogenesis and the formation of new blood vessels is a requirement for intact tissue as well as regeneration. The regulation is controlled by growth factors, chemokines, endothelial cell-specific receptors and adhesion molecules [1]. Impaired angiogenesis is associated with various pathological conditions including cancer, diabetic retinopathy, asthma, autoimmune disorders and infectious diseases [2,3]. Moreover, angiogenesis plays an important role in organ growth and wound healing [4,5], as blood vessels supply tissues with oxygen and nutrients and remove waste products [6]. Vascularization, essential in wound healing, is regulated by several growth factors: basic fibroblast growth factor (bFGF) [7], platelet derived growth factor (PDGF), epidermal growth factor (EGF) and vascular endothelial growth factor (VEGF) [8]. Pro-inflammatory mediators e.g., interleukins and interferons stimulate the endothelium to produce various chemokines [9-12]. VEGF activates endothelial cells to proliferate, migrate, and to form sprouts. Moreover, VEGF is involved in blood vessel formation, wound healing, and organ regeneration $[13,14]$. VEGF increases myoblast migration and inhibits apoptosis in the skeletal muscle in vivo [15,16]. Moreover, it is suggested that VEGF can modulate myoblasts, which contributes to the recruitment of progenitor cells in regenerating muscle. 
Therefore, it is an indicator for common processes with identical triggers for regeneration and angiogenesis $[17,18]$.

Glucocorticoids (GCs) are endogenous stress hormones with anti-inflammatory properties and used to treat inflammatory disorders $[19,20]$. GCs decrease the production of several pro-inflammatory cytokines and chemokines. including IL-6 [21-23] and thereby limiting inflammation [24]. However, high therapeutic doses and prolonged phases of medication can induce undesired side-effects, including osteoporosis, diabetes and hypertension [25]. Additionally, GCs inhibit pro-inflammatory signalling [26] and angiogenesis. In fact, suppression of angiogenesis contributes to impaired wound healing caused by GC excess.

Previous studies suggest that GCs inhibit the process of angiogenesis by downregulation of the glucocorticoid receptor (GR) [27], resulting in the inhibition of VEGF [28,29]. Others found that GCs blocked the VEGF-induced tube-like-structure (TLS) of endothelial cells, but without any effects on proliferation or migration [15]. This resulted in a decreased formation of cell-cell contacts. Similar effects by using high and prolonged doses of GCs can result in skeletal muscle atrophy, caused by the catabolic effects [30] and further in muscle wasting [31,32]. Dex impact on primary human myoblasts was investigated in our previous study [33]. We found that dex reduced protein expression of myosin heavy chain $(\mathrm{MyHC})$ and elevated the expression of the atrophy related ubiquitin ligase MuRF-1. However, beside the fact that only limited studies with human myoblasts exist, neither the mechanisms nor the interaction between myoblasts or endothelial cells under the influence of dex has been described. There are no reports describing the effects of dex on both cell types in a co-culture system in vitro, which could show and analyze the mechanisms of dex administration on the interaction of these two cell types.

The hypoxia-inducible transcription factor-1 (HiF-1) increases angiogenesis in normal tissues [34]. It is reported that hypoxia reduces the GR expression and attenuates the anti-inflammatory effects of GCs [35,36]. Dex impairs HiF-1 $\alpha$ gene expression [37], but the GR activation is associated with enhanced HiF-1 activity, which is partly in contrast to other studies [38]. GCs play a key role in the suppression of inflammation by inhibiting the transcription of the cytokines through binding to the GR and the activated GR interacts with several transcription factors in a positive or negative manner [39].

Our hypothesis is that dexamethasone impairs angiogenesis leading to muscle atrophy or inhibited muscle regeneration. Therefore, this study aims to elucidate the effect of dexamethasone (dex) on HUVECs under different conditions in mono- and co-culture with myoblasts to evaluate growth behavior and dex impact with regard to muscle atrophy and muscle regeneration. We investigated the effect of dex on endothelial cells under different growth conditions and in various environments. Additionally, we analyzed the influence of VEGF under the previously described conditions. In a second part, we established and evaluated a co-culture system of primary human myoblasts and HUVECs to analyze their growth behavior and interaction after dex administration in order to define effects leading to muscle atrophy and inhibited muscle regeneration.

\section{Results}

\subsection{Dex Influences Cell Viability Depending on the Presence of VEGF}

To investigate the influence of dex on HUVEC viability and proliferation, the AlamarBlue ${ }^{\circledR}$ cell viability assay was performed after $24 \mathrm{~h}$ and $48 \mathrm{~h}$ treatment. HUVECs were treated with $10 \mu \mathrm{M}$ or $100 \mu \mathrm{M}$ Dex, or left untreated (control), in medium containing VEGF (HM1) or without VEGF (HM1-V) (Figure 1). The treatment of HUVECs with $10 \mu \mathrm{M}$ dex resulted in a significantly increased fluorescence intensity corresponding to better viability and faster proliferation compared to the untreated control after 24 and $48 \mathrm{~h}$ in HM1 (Figure 1). In contrast, proliferation of cells treated with $100 \mu \mathrm{M}$ was significantly lower compared to the control group and to the group with $10 \mu \mathrm{M}$ dex in HM1 after the same time points. 


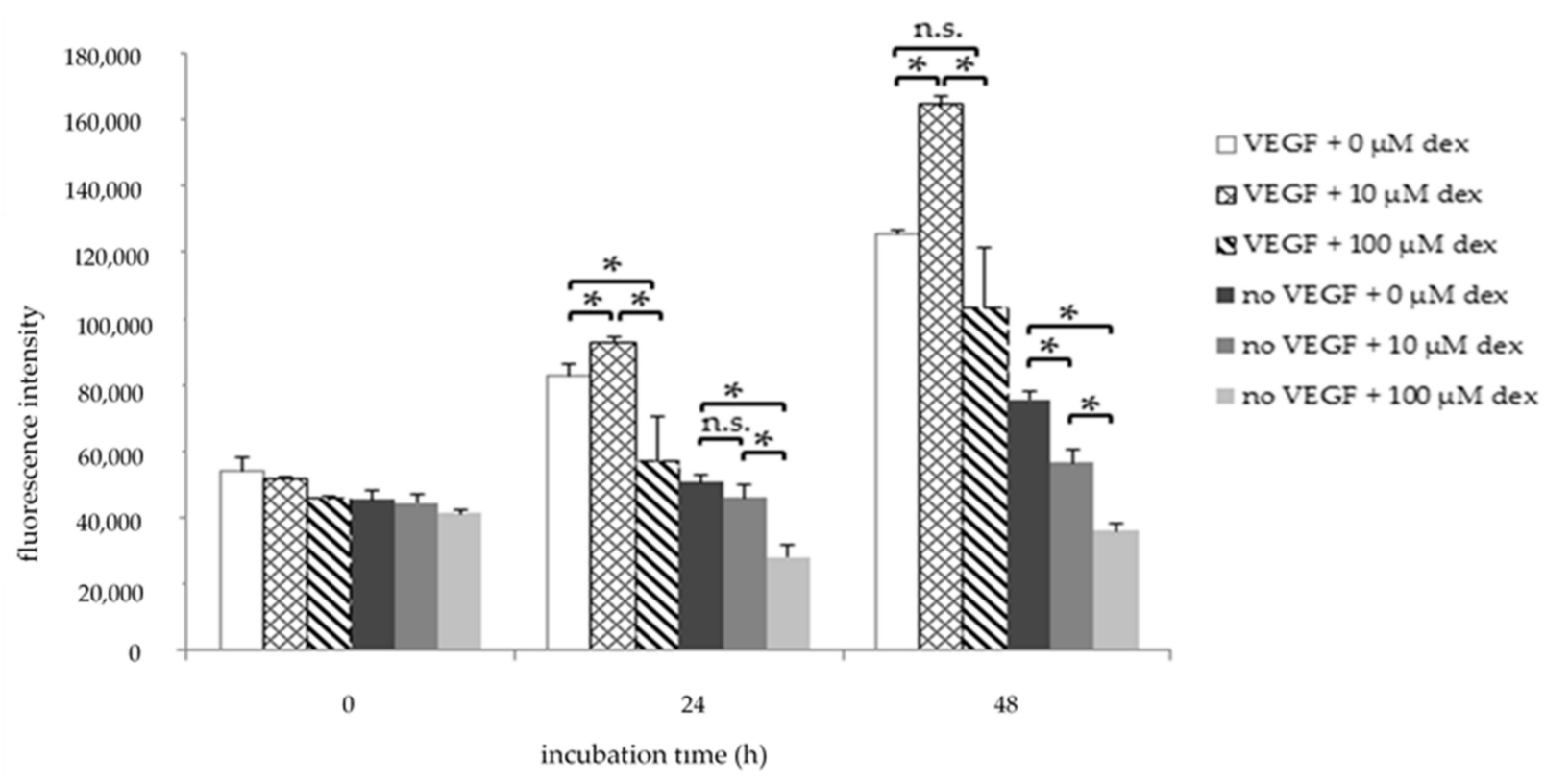

Figure 1. Viability assay of HUVECs after 0, 24, and 48 h in HM1 medium (with VEGF) or in HM1-V medium (without VEGF) and $\operatorname{dex}(10,100 \mu \mathrm{M})$. Results are presented as bar charts; error bars show the standard deviation $(n=3)$. A $p$ value $<0.05$ indicate statistical significance $\left({ }^{*} p<0.05\right)$, n.s. $=$ non-significant.

When VEGF was excluded from the medium (HM1-V), $10 \mu \mathrm{M}$ and $100 \mu \mathrm{M}$ Dex treatment decreased HUVEC cell viability most pronounced at $48 \mathrm{~h}$, but also already at $24 \mathrm{~h}$, compared to the control (Figure 1).

In order to show that the effect was specific to dex we performed the same experiment with the GR-antagonist RU-486. The inhibitor reversed the dex effects, demonstrating the specificity (Figure S1).

\subsection{Dex Inhibits TLS Formation Depending on VEGF Presence}

In order to analyze HUVECs ability to form their typical TLS, they were seeded in Matrigel in HM1 (Figure 2) or in HM1-V medium (Figure S2) and incubated with or without dex for $24 \mathrm{~h}$. The percentage of the number of nodes, junctions, total length, and the total segment length was analyzed and compared to the untreated control. Representative example images of the TLS assay are shown in the Supplementary Materials (Figure S2).

The number of nodes as well as the total segment length were significantly reduced after the incubation with $10 \mu \mathrm{M}$ (Figure 2a). Incubation with $100 \mu \mathrm{M}$ resulted in a significant decrease in all parameters measured.

Investigations of HUVECs in HM1-V medium revealed no significant changes in the number of nodes, junctions, total length, and total segmental lengths $24 \mathrm{~h}$ after incubation with $10 \mu \mathrm{M}$ dex compared to untreated control. However, incubation with $100 \mu \mathrm{M}$ resulted in a significant decrease in all parameters measured (Figure S3).

In summary, the higher the amount of dex, the higher the reduction of the number of nodes, number of junctions, total length and total segment length. Moreover, in the presence of VEGF, dex reduces TLS formation even further.

\subsection{The Influence of Dex on Gene Expression Is Independent of the Cells Growing in a 2D or 3D Matrix}

To further analyze possible effects of dex under the influence of VEGF, gene expression analyses were performed for CD31,VEGF, $H i F 1 \alpha$, and GR. In order to detect any influences of dex on inflammation, gene expression of pro-and anti-inflammatory genes IL-6 and IL-10 was analyzed. In order to determine possible changes in gene expression, depending on the environment, HUVECs were seeded in Matrigel (Figure 3a) or in normal plastic culture plates (Figure 3b) under the same conditions. 
a

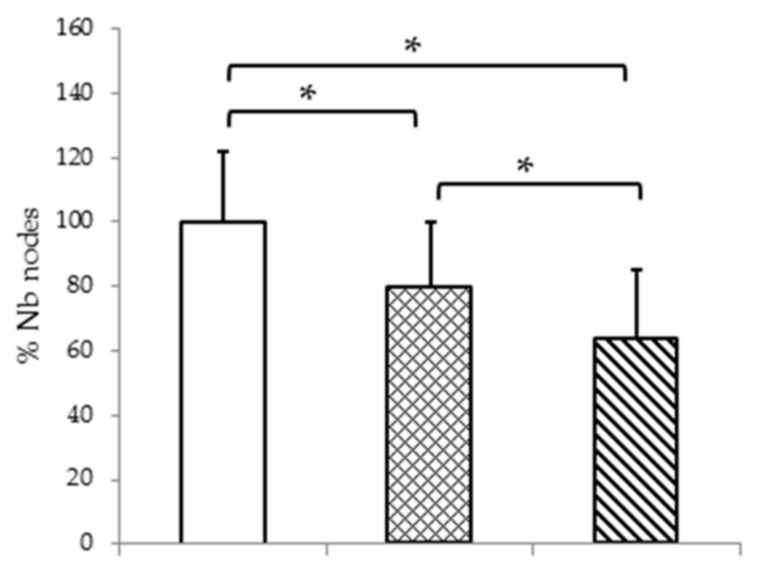

C

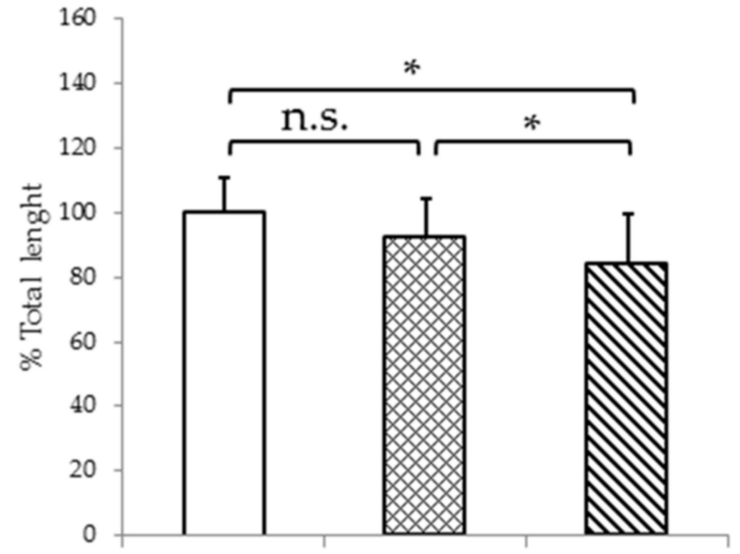

b

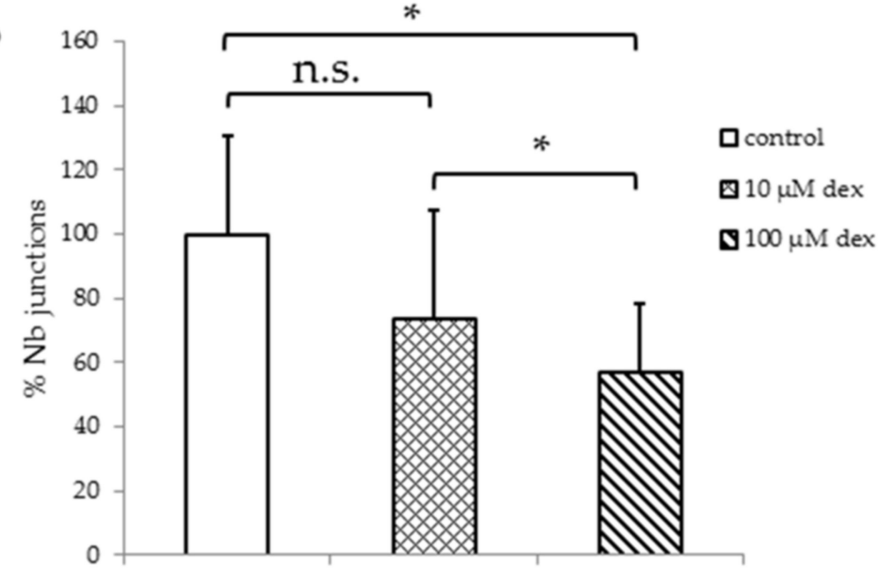

d

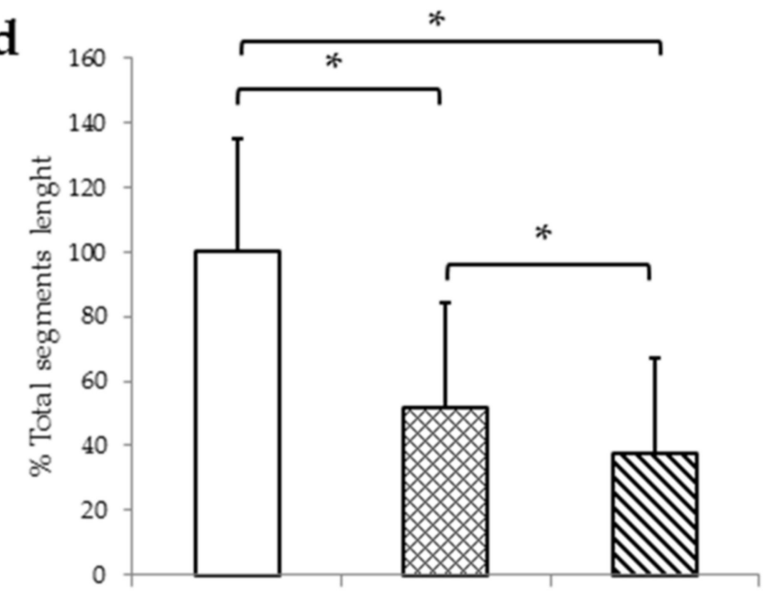

Figure 2. TLS assay of HUVECs after $24 \mathrm{~h}$ in HM1 with 10 and $100 \mu \mathrm{M}$ dex. Results are presented as bar charts; error bars show the standard deviation $(n=3)$. Quantitative analyzes were performed for number of nodes (a), number of junctions (b), total length (c), and the total segments length (d). Data were normalized to a control of $100 \%$. A $p$ value $<0.05$ indicate statistical significance $\left({ }^{*} p<0.05\right)$, n.s. $=$ non-significant.

Regarding CD31 gene expression changes, it was only significantly suppressed after culture in Matrigel and incubation with $100 \mu \mathrm{M}$ dex with VEGF compared to the untreated control group. When cells were cultured on plastic gene expression of the surface protein CD31 (Figure 3b), there was a statistically significant decrease after the treatment with $10 \mu \mathrm{M}$ dex when cells were cultured in HM1 compared to the untreated control cells. The incubation with $100 \mu \mathrm{M}$ dex did not influence $C D 31$ gene expression.

There were no statistical differences detected in VEGF gene expression in Matrigel compared to control cells at any condition tested (Figure 3a). When cells were cultured on plastic, only incubation with $10 \mu \mathrm{M}$ dex led to a statistically significant upregulation in $V E G F$ gene expression in VEGF containing medium. $100 \mu \mathrm{M}$ dex led to an upregulation that was not statistically significant, however.

Analysis of the transcription factor HiF1 $\alpha$ gene expression after culture in Matrigel revealed only a significant downregulation after the incubation with $10 \mu \mathrm{M}$ dex in HM1-V. The expression of HiF1 $\alpha$ (Figure $3 \mathrm{~b}$ ) after culture on cell culture plates was not regulated in any condition tested.

Regarding gene expression of pro-and anti-inflammatory genes IL-6 and IL-10, no statistically significant changes were observed after culture in Matrigel with the exception that IL-10 was significantly downregulated after the treatment with $10 \mu \mathrm{M}$ dex in HM1. Regarding culture in cell culture plates, $100 \mu \mathrm{M}$ dex led to a significant upregulation of $I L-6$ (without VEGF) and IL-10 gene expression (with VEGF) compared to untreated control cells (Figure 3b). 
The gene expression of $G R$ was statistically significantly reduced when cells were cultured in Matrigel without VEGF and $10 \mu \mathrm{M}$. Cell culture in cell culture plates resulted in no significant gene expression changes independent from culture conditions used.
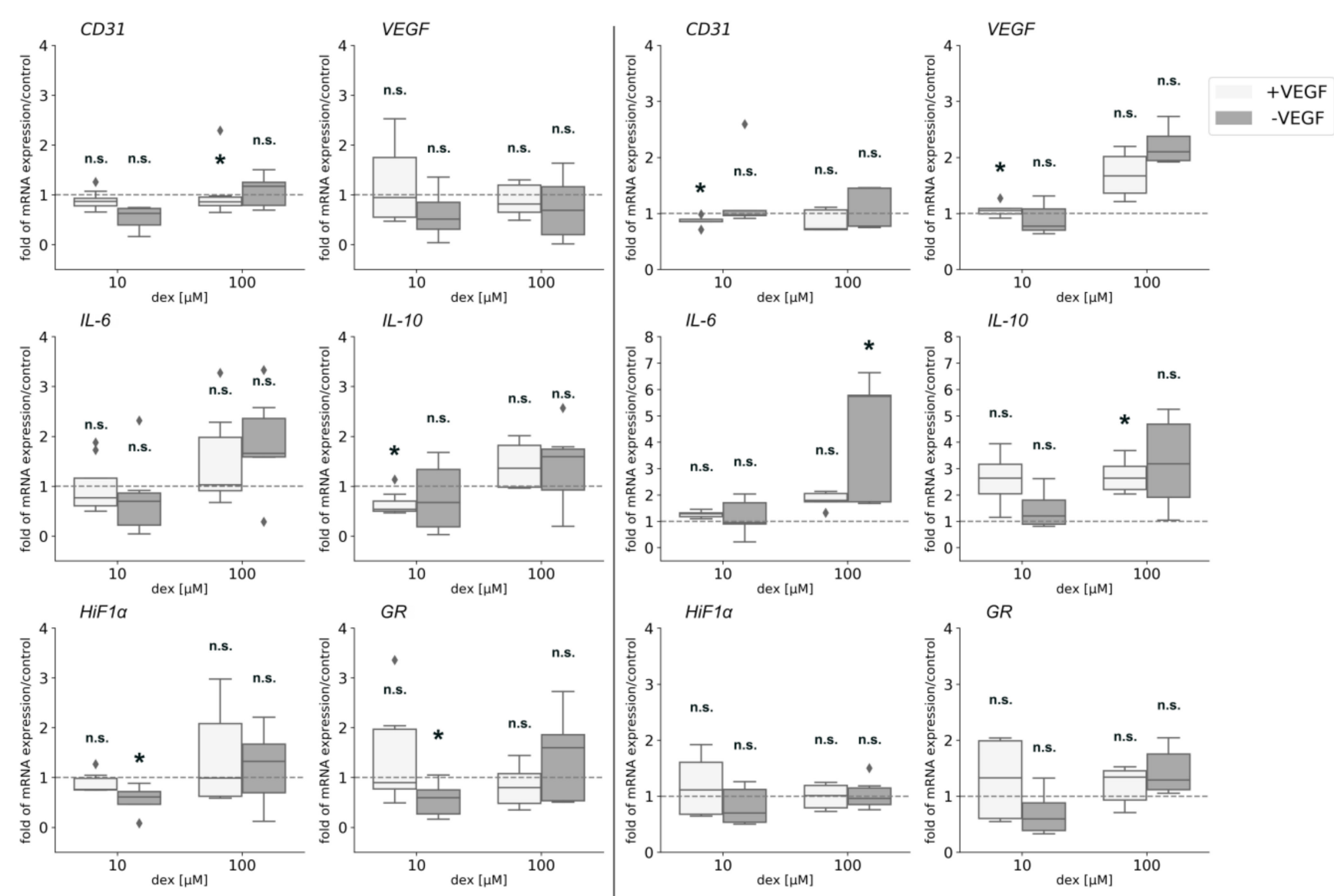

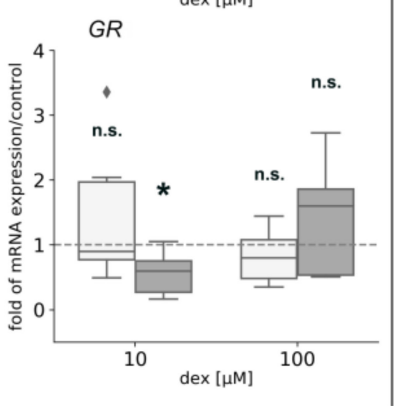

(a)

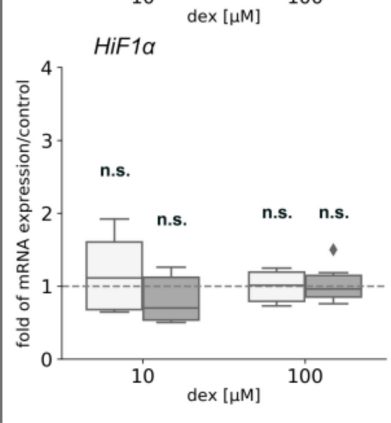

(b)

Figure 3. Gene expression analyses for CD31, VEGF, IL-6, IL-10, HiF1 $\alpha$, and GR of HUVECs in HM1 medium (with VEGF) or in HM1-V medium (without VEGF) and 10 and $100 \mu \mathrm{M}$ dex for $24 \mathrm{~h}$. HUVECs were seeded in Matrigel (a) or on plastic culture plates (b). The mRNA levels were normalized to GAPDH and calculated as ratios in relation to the untreated control group (interrupted line). Results are presented as medians and quartiles $(n=3)$, and $p$ values $<0.05$ indicate statistical significance $\left({ }^{*} p<0.05\right)$, n.s. $=$ non-significant. Outliners are presented as rhombs.

\subsection{Cell Viability Depends on Exogenous Growth Factors}

In order to define the effect of different media and their supplements in combination with dex on HUVECs, they were analyzed after dex treatment without access to growth factors. Viability (Figure 4) and gene expression analyses (Figures 5 and 6) were performed using the following media: (i) EBM-2 medium alone (EBM-2) (Table 1, negative control); (ii) EBM-2 medium with serum, hydrocortisone, heparin, and ascorbic acid, but without growth factors (EBM-2 $\varnothing \mathrm{GF}$ ) and hydrocortisone either with or without dex. Additionally, cells were maintained in DM (Table 1), which was normally used for myoblast differentiation with and without dex for further co-culture experiments (Figures $4 \mathrm{~b}$ and 6 ). 


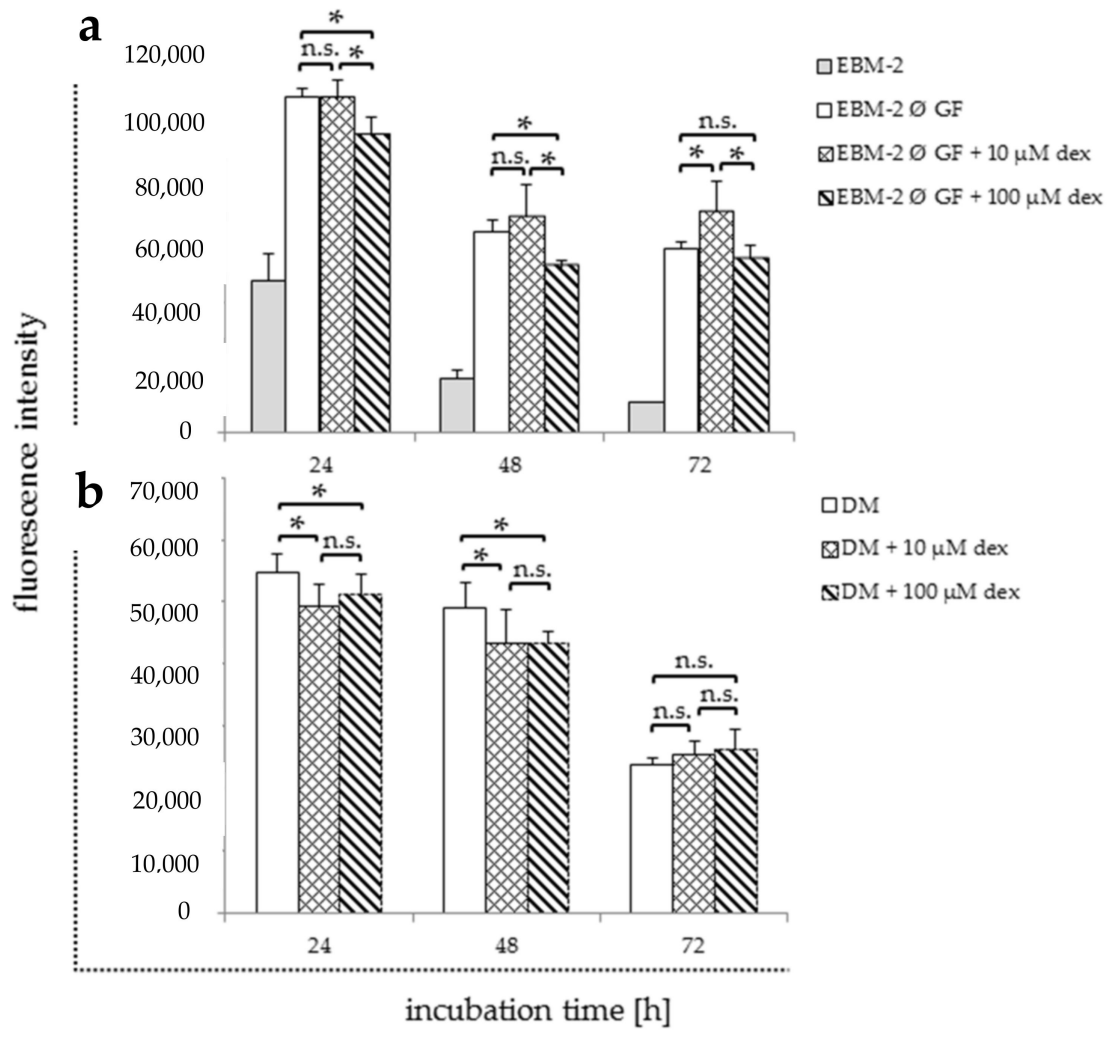

Figure 4. Viability assay of HUVECs 24,48 , and $72 \mathrm{~h}$ after the incubation with and without dex in different media compositions ((a): EBM-2 without growth factors; (b): DM). Results are presented in bar charts; error bars show the standard deviation $(n=3)$. A $p$ value $<0.05$ indicate statistical significance $\left({ }^{*} p<0.05\right)$, n.s. $=$ non-significant.
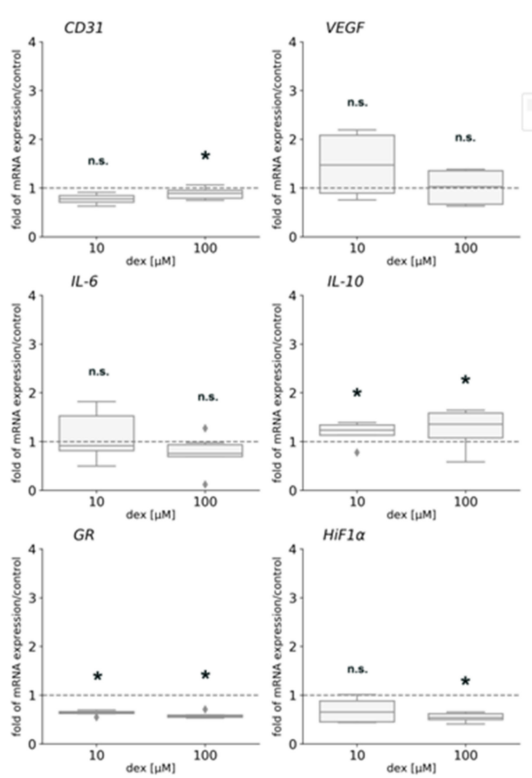

(a)
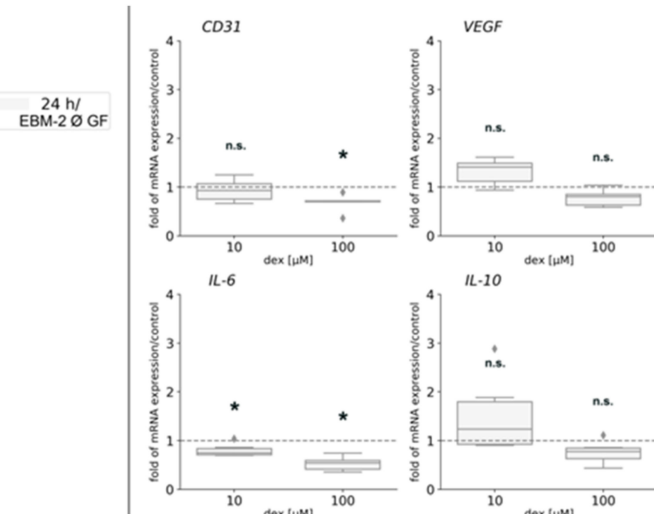

$24 \mathrm{~h} / \mathrm{DM}$

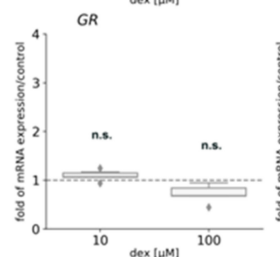

(b)

Figure 5. Gene expression analyses of HUVEC maintained in EBM-2 $\varnothing$ GF (a) and in DM (b) for CD31, VEGF, IL-6, IL-10, GR, and HiF1 . The mRNA levels were normalized to GAPDH and calculated as ratios in relation to the untreated control group (interrupted line). Results are presented as medians and quartiles $(n=3)$, and $p$ values $<0.05$ indicate statistical significance $(* p<0.05)$, n.s. $=$ non-significant. Outliners are presented as rhombs. 


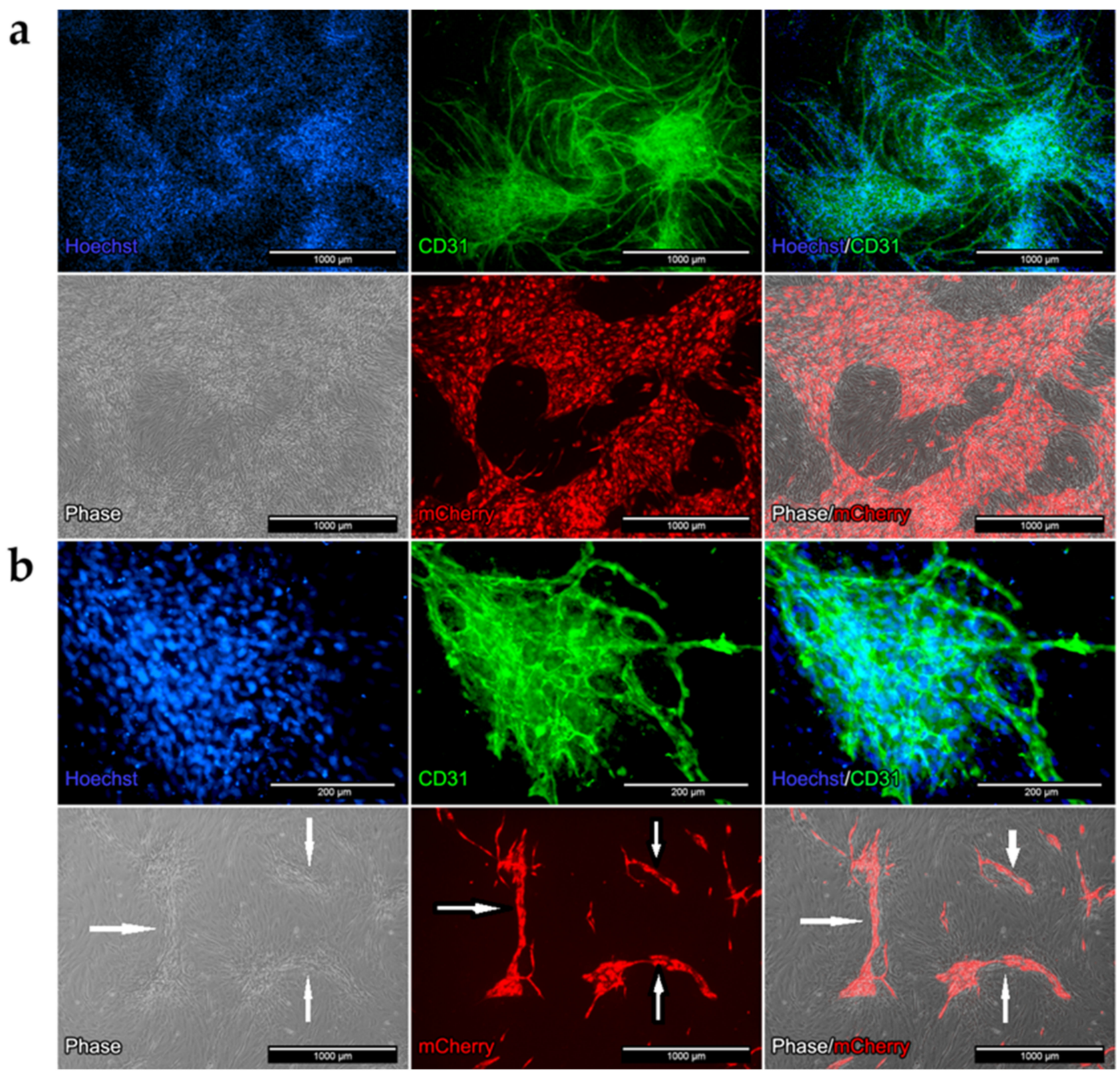

Figure 6. Immunofluorescence of the co-culture after 5 days in HM1/DM (a) and in DM (b) medium. Cells were stained with CD31 specific antibody (green). Nucleus staining was performed with Hoechst dye (blue). Phase contrast images of the co-culture $((\mathbf{a}, \mathbf{b})$, grey). HUVECs transduced with the mCherry vector $((\mathbf{a}, \mathbf{b})$, red $)$ in the co-culture; overlay of the phase contrast images and the transduced HUVECs (red, grey). Myoblasts were not transduced.

The negative control showed a rapid reduction in cell viability over all time points (Figure 4a). The treatment with $10 \mu \mathrm{M}$ significantly increased proliferation only after $72 \mathrm{~h}$ compared to the untreated EBM-2 without GF control (Figure 4a). The treatment with $100 \mu \mathrm{M}$ significantly reduced proliferation rate compared to control after 24 and $48 \mathrm{~h}$.

Maintaining cells in DM and treating them with 10 and $100 \mu \mathrm{M}$, dex significantly decreased the proliferation after 24 and $48 \mathrm{~h}$ compared to the untreated DM control (Figure $4 \mathrm{~b}$ ). However, no statistically significant differences were observed between all groups after $72 \mathrm{~h}$. 
Table 1. Cell culture media and different HUVEC cell media and kits.

\begin{tabular}{|c|c|c|}
\hline Cell Type & Medium & Formulation \\
\hline HUVEC & growth medium (HM1) & 5\% FCS, EBM-2, EGM ${ }^{\mathrm{TM}}-2$ BulletKit ${ }^{\mathrm{TM}}$ \\
\hline HUVEC & growth medium without VEGF (HM1-V) & 5\% FCS, EBM-2, EGM ${ }^{\mathrm{TM}}-2$ BulletKit ${ }^{\mathrm{TM}}$, except VEGF \\
\hline HUVEC & without supplementation (EBM-2) & EBM-2 \\
\hline HUVEC & without growth factors (GF) (EBM-2 Ø GF) & $\begin{array}{l}\text { EBM-2 + 5\% FCS, ascorbic acid, heparin, } \\
\text { gentamicin/amphotericin B }\end{array}$ \\
\hline Myoblasts & growth medium (MM1) & DMEM/F-12, 10\% FCS, $2.5 \mathrm{ng} / \mathrm{mL}$ bFGF \\
\hline Myoblasts & differentiation medium (DM) & DMEM/F-12, $5 \%$ HS \\
\hline CoCulture & $\begin{array}{l}\text { induction medium for myo-or angiogenesis medium } \\
(1: 2) \mathrm{HM} 1 / \mathrm{DM}\end{array}$ & $\begin{array}{l}\text { EBM-2 + EGM-2 Bullet Kit } \\
\text { DMEM/F-12, 5\% HS (1:2) }\end{array}$ \\
\hline
\end{tabular}

\subsection{Gene Expression Is Affected by Dex and Depends on the Media}

To further analyze possible effects of dex under the influence of growth factors and different media compositions, gene expression analyses were performed for CD31,VEGF, $H i F 1 \alpha$, and GR. In order to detect any influences of dex on inflammation, gene expression of pro-and anti-inflammatory genes IL- 6 and IL-10 was analyzed.

CD31 gene expression was not statistically significantly affected by $10 \mu \mathrm{M}$ dex maintaining cells in EBM-2 $\varnothing$ GF or DM (Figure 5a; Figure 5b). However, the treatment with $100 \mu \mathrm{M}$ significantly decreased its expression compared to the untreated control cells in both media (Figure 5a,b). VEGF gene expression was not statistically changed after dex treatment in both media (Figure $5 b$ ). HiF1 $\alpha$ gene expression was not affected by the low concentration $(10 \mu \mathrm{M})$ but its expression was significantly downregulated after incubation with the high dex concentration (Figure 5a) in EBM-2, whereas no changes were observed after incubation in DM (Figure 5b).

Regarding gene expression of pro-and anti-inflammatory genes $I L-6$ and $I L-10$, a contrary gene expression was observed: in EBM-2 media, dex had no significant effect on $I L-6$ gene expression (Figure $5 a$ ), whereas gene expression of $I L-10$ was statistically significantly upregulated after the treatment with 10 and $100 \mu \mathrm{M}$ dex compared to the untreated control (Figure 5a). Concerning incubation in DM, gene expression of IL-6 was significantly downregulated by 10 and $100 \mu \mathrm{M}$ dex compared to the untreated control cells (Figure $5 b$ ), whereas IL-10 gene expression changed to be not statistically significant after the treatment with both concentrations for $24 \mathrm{~h}$ (Figure $5 \mathrm{~b}$ ).

The gene expression of the GR was significantly decreased in HUVECs after dex incubation compared to the untreated cells in EBM-2 (Figure 5a). whereas no changes were observed after incubation in DM.

\subsection{Designing a Co-Culture System of Human Endothelial Cells with Primary Myoblasts}

A co-culture of primary human myoblasts and human endothelial cells has been established to assess interactions of cell types with regard to the development of muscle atrophy, muscle regeneration, and the role of angiogenesis.

First, we investigated the behavior of both cell types, especially of HUVECs, in different media compositions (Table 2) as HUVECs require a mixture of different growth factors to proliferate and survive. Figure $\mathrm{S} 4$ shows both cell types as mono-and co-cultures in the applied different media.

Table 2. Media composition for co-culture evaluation.

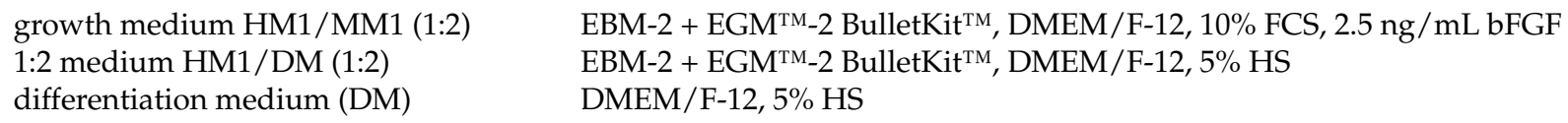

In contrast to HUVEC mono-cultures in DM (contains no growth factors, Figure S4b), HUVECs did not undergo apoptosis in co-culture with myoblasts in DM medium (Figure S4e). 
To explain this effect, we hypothesized that primary myoblasts produced growth factors, which allowed HUVECs to survive.

\subsection{Formation of Vessel-Like Structures in the Co-Culture}

To further define the characteristics of the co-culture, immunofluorescence staining using a specific antibody for the angiogenic marker CD31 (Figure 6) was performed. In addition, HUVECs were transduced with the mCherry-protein to distinguish the cell types.

Cells in the co-culture stained positive for CD31 protein in the medium mixture HM1/DM. In the phase contrast images, the large areas can be clearly identified as endothelial cells (Figure 6a). The CD31 staining showed wide branched, elongated, and tubular structures, but hardly any bulges. In the co-culture without growth factors (DM), cells were positive for the angiogenic marker CD31 after 5 days. In the phase contrast images, small, elongated bulges of HUVEC cells were visible (Figure $6 \mathrm{~b}-$ white arrows). Staining with CD31 confirmed small, elongated tubes and tubular branches indicating the process of angiogenesis performed by endothelial cells.

\subsection{Dex Reduces the Angiogenic Potiential of HUVECs in the Co-Culture}

To analyze the influence of dex on bulge formation in a co-culture system, HUVECs and myoblasts were incubated for $96 \mathrm{~h}$ in DM and analyzed after 48 and $96 \mathrm{~h}$ (Figure S5).

After $48 \mathrm{~h}$ there were no visible differences between the untreated control and the treated groups with 10 and $100 \mu \mathrm{M}$ dex (Figure S5). In the control as well as in both treated groups, cells started to form multiple bulges. After $96 \mathrm{~h}$ (Figure S5) fewer and less pronounced bulges were visible in the treated groups with 10 and $100 \mu \mathrm{M}$ dex compared to the untreated control group. Moreover, the bulges in the control seemed to be stronger than in the treated groups.

\subsection{Dex Impairs Angiogenesis and Decreases CD31 Protein Expression in the Co-Culture}

To analyze the protein expression in the co-culture as well as the influence of dex on cells, stainings for the myotube marker MyHC (Figure 7) and the angiogenic marker CD31 (Figure 8) were performed.

Positive stained cells for the myotube marker $\mathrm{MyHC}$ and the formation of multinucleated cells were observed in all groups (Figure 7). The qualitative analysis showed no reduction in the formation of multinucleated myotubes and myotube diameter after dex treatment.

Figure 8 shows the positive CD31 antibody staining of HUVECs after $96 \mathrm{~h}$ in the coculture. In the control group a close meshed formation of TLS could be detected. Both dex treated group showed no close meshed bulges, but rather long sustained and undefined structures (Figure 8).

To summarize, CD31 and MyHC staining of co-cultures revealed that dex had a higher impact on endothelial cells than on human myoblasts.

\subsection{Dex Reduces VEGF Secretion of Myoblast and Decreases Angiogeneses}

To determine if primary myoblasts produce VEGF and whether this secretion was influenced after dex treatment, a VEGF ELISA was performed. The results presented in Figure 9 shows that VEGF release increased continuously in the co-culture in the control group. Treatment with 10 and $100 \mu \mathrm{M}$ dex drastically reduced the released amount of VEGF. No differences in the released amount of VEGF between 10 and $100 \mu \mathrm{M}$ dex were observed. 


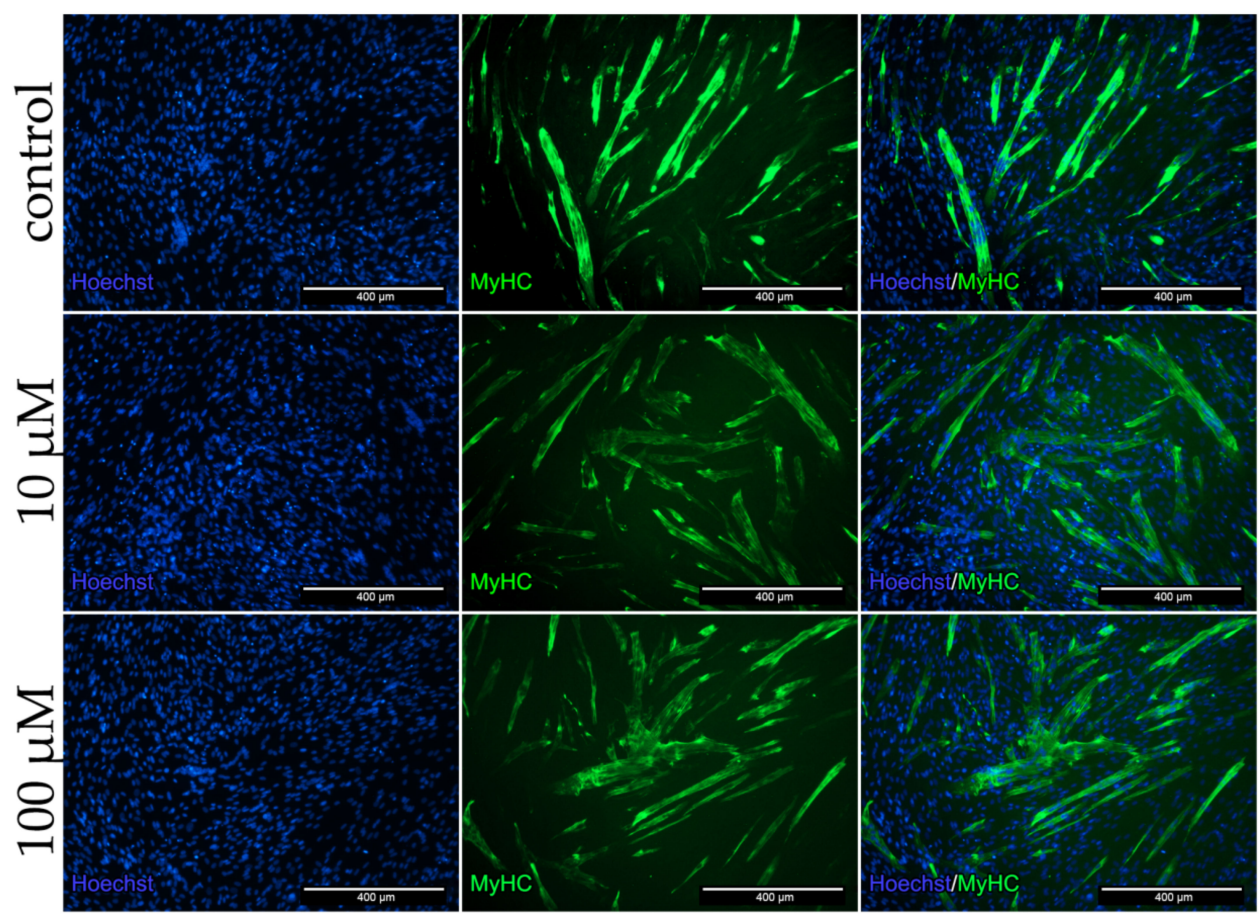

Figure 7. Immunofluorescence staining for MyHC after $96 \mathrm{~h}$ incubation in DM with 10 and $100 \mu \mathrm{M}$ dex in the co-culture and untreated control. Myotubes were stained with MyHC (MyHC, green) specific antibody. Nucleus staining was performed using Hoechst dye (blue).

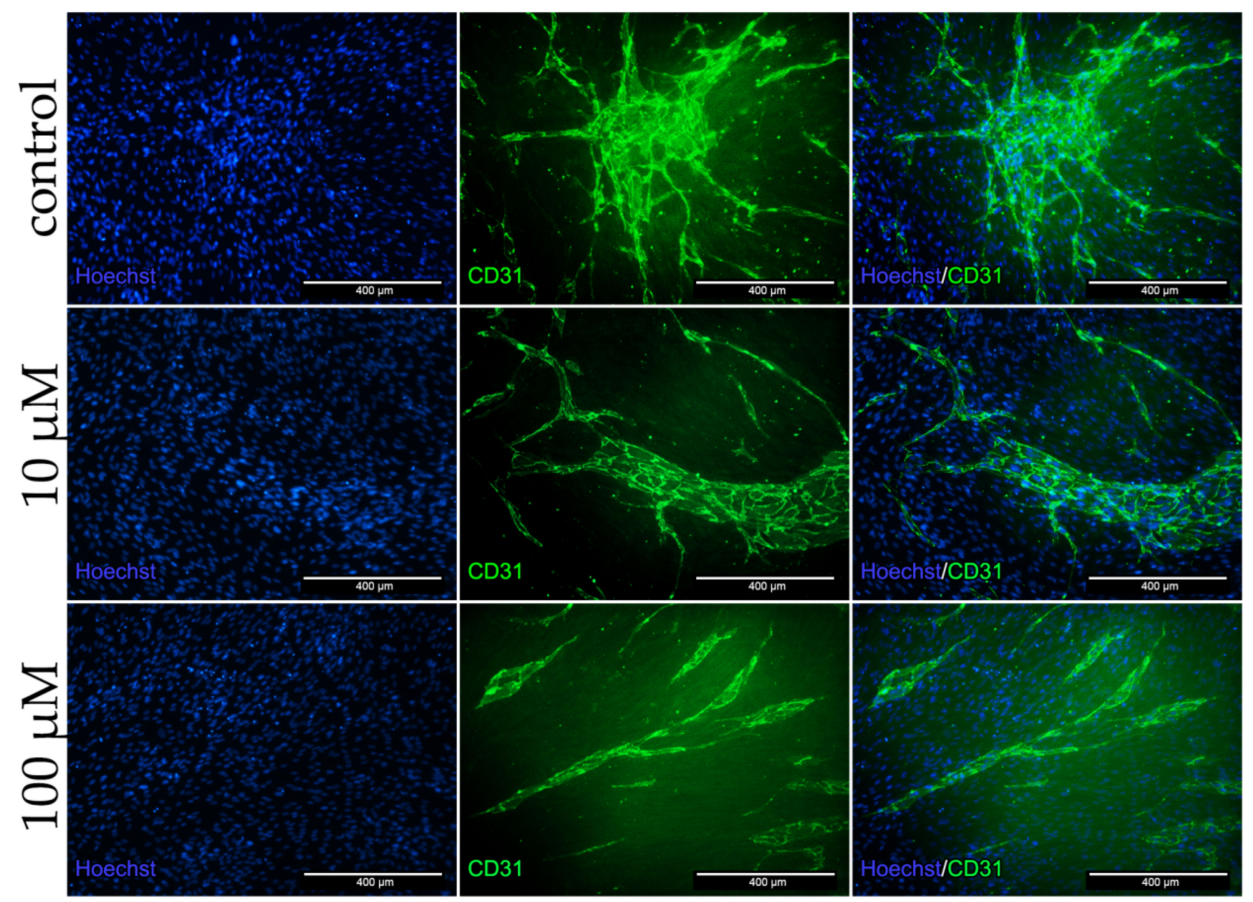

Figure 8. Immunofluorescence staining for CD31 after $96 \mathrm{~h}$ incubation in DM with 10 and $100 \mu \mathrm{M}$ dex and untreated control in the co-culture. HUVECs were stained with CD31 (green) specific antibody. Nucleus staining was performed using Hoechst dye (blue). 


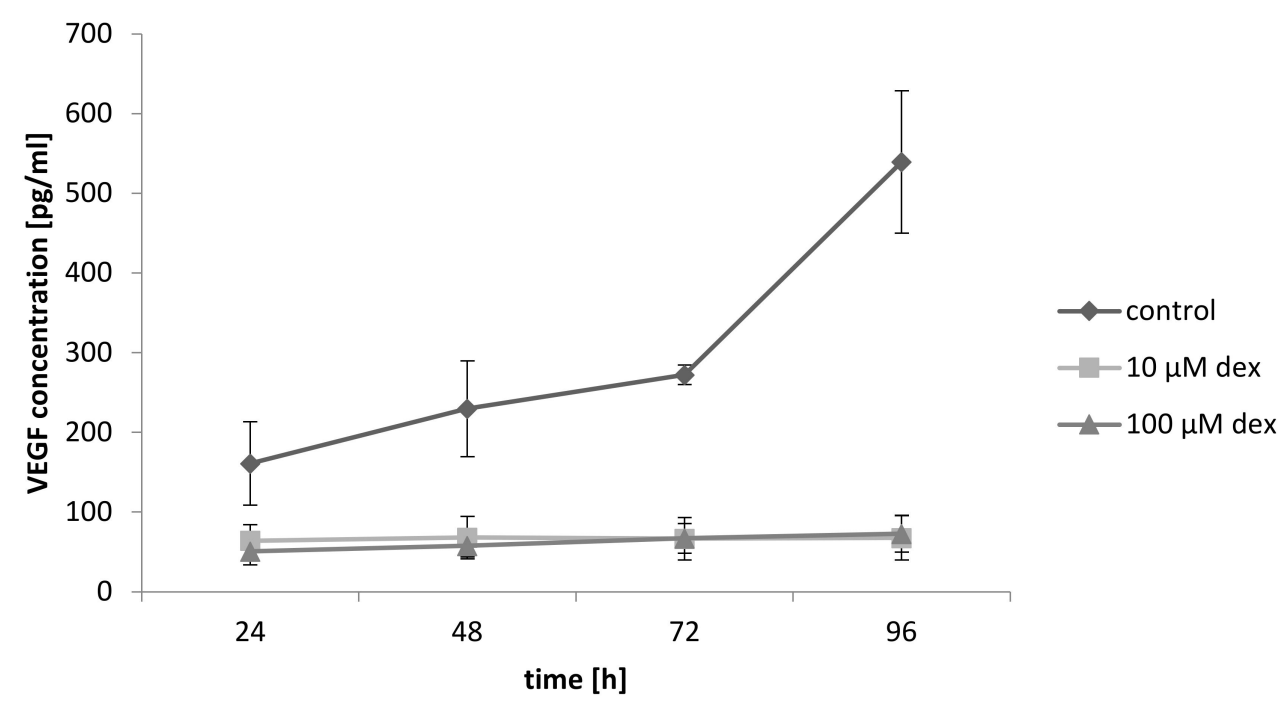

Figure 9. VEGF release in the co-culture with and without dex after $24,48,72$, and $96 \mathrm{~h}$. Results are represented in a line diagram and error bars show the standard deviation $(n=3)$.

2.11. Dex Enhances the Expression of Myogenic Transcription Factors but Represses Angiogenesis in the Co-Culture

In order to determine the effects of dex on gene expression in the co-culture system, qPCR analyses for various markers were performed (Figure 10).

$C D 31$ and VEGF gene expression was significantly downregulated when cells were incubated with $10 \mu \mathrm{M}$ dex for $24 \mathrm{~h}$ and $48 \mathrm{~h}$ and when they were incubated with $100 \mu \mathrm{M}$ for 48 hours. Gene expression of IL- 6 was significantly downregulated after both incubation times and both concentrations of dex. IL-10 gene expression was not influenced by dex treatment (data not shown). Gene expression analysis of HiF1 $\alpha$ was only significantly downregulated $48 \mathrm{~h}$ after the incubation with 10 and $100 \mu \mathrm{M}$. The expression of the GR was not influenced by dex, neither after 24 nor after $48 \mathrm{~h}$. The myogenic factor $M y o D$ showed a significantly higher expression level after $24 \mathrm{~h}$ incubation with $10 \mu \mathrm{M}$ dex and after $48 \mathrm{~h}$ with $100 \mu \mathrm{M}$ dex in the co-culture. The transcription factor $M y o G$ was significantly upregulated by $10 \mu \mathrm{M}$ after 24 and $48 \mathrm{~h}$, but $100 \mu \mathrm{M}$ influenced and upregulated its expression only after $48 \mathrm{~h}$.

For our studies, we used dex concentrations of 10 and $100 \mu \mathrm{M}$. Regarding studies with glucocorticoids, various concentrations are used ranging from $10 \mathrm{nM}$ to $100 \mu \mathrm{M}$. We decided to use these two concentrations as Han et al. [40] demonstrated that $100 \mu \mathrm{M}$ dex exhibited the most prominent atrophic effect on $\mathrm{C} 2 \mathrm{C} 12$ myoblasts. Moreover, Shin et al. showed that C2C12 myotubes responded in a dose-dependent manner to increasing dex concentrations (10-50-100 $\mu \mathrm{M})$ [41]. Wang et al. [42] and others [43] observed that $100 \mu \mathrm{M}$ dex suppressed muscle protein synthesis and enhanced proteolysis-thereby representing a potential model of muscle atrophy or inhibited muscle regeneration [44]. Doses in the nanomolar range stimulate myogenesis, and thus why we excluded these concentrations from our setting. Moreover, we and others [33] could show that the applied high concentrations at least partially induce myogenic gene expression. As we wanted to imitate atrophic conditions as described in the cited literature, we chose the concentrations of 10 and $100 \mu \mathrm{M}$ to characterize the effects on HUVEC, which has, to our knowledge, not been analyzed before. 

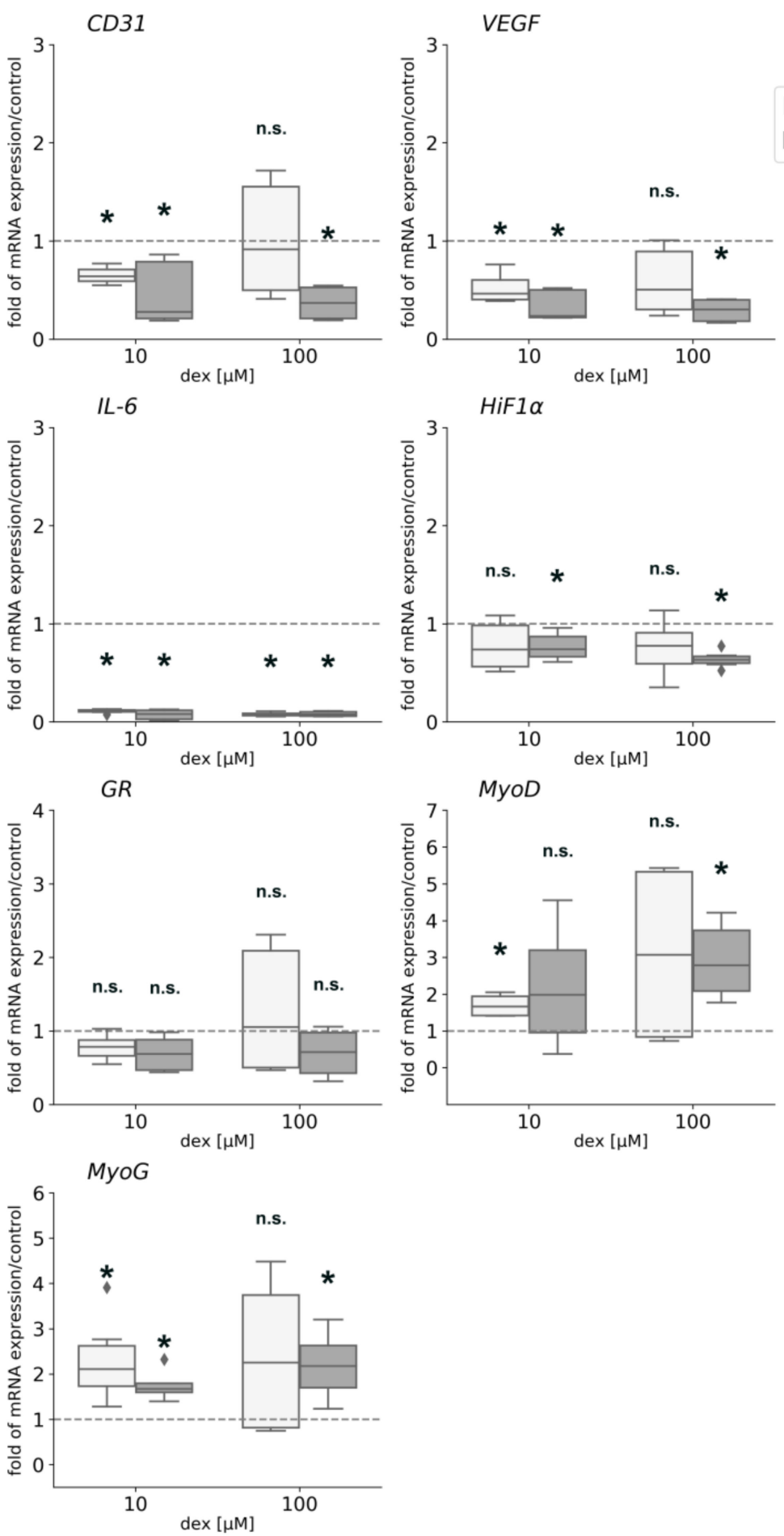

Figure 10. Gene expression analyses for CD31, VEGF, IL-6, HiF1 $\alpha, G R, M y o D$, and MyoG in the co-culture after 24 and $48 \mathrm{~h}$ in DM with or without 10 or $100 \mu \mathrm{M}$ dex. The mRNA levels were normalized to GAPDH and calculated as ratios in relation to the untreated control group (interrupted line). Results are presented as medians and quartiles $(n=3)$, and $p$ values $<0.05$ indicate statistical significance $\left({ }^{*} p<0.05\right)$, n.s. $=$ non-significant. Outliners are presented as rhombs.

\section{Discussion}

3.1. Dex Influence on Endothelial Cells Cultured in Mono-Culture Depends on Different Factors

Our results show that $10 \mu \mathrm{M}$ dex significantly enhanced cell proliferation, whereas $100 \mu \mathrm{M}$ caused the opposite effect (Figure 1). It has already been demonstrated that high 
concentrations of GCs inhibit the proliferation of human endothelial cells [45]. The increase in proliferation after cells were treated with $10 \mu \mathrm{M}$ dex could result from the hydrocortisone supplementation in the medium as well as from an additional low concentration of dex leading to an increase in cellular stress. Cells cultured in medium without VEGF had a slower proliferation rate and dex had a higher effect on HUVECs when VEGF was absent. These results confirm that VEGF plays a central role in the proliferation of HUVECs [15]. Our results show that high dex concentrations repress endothelial cell viability and proliferation and confirm its anti-angiogenic effect. This effect was reversed after incubation with the GR antagonist RU-486, showing the specific effect of dex.

To figure out the influence of other growth factors in combination with dex on HUVECs viability and proliferation, cells were maintained in different media with different supplements and with and without dex. Our results showed that HUVECs require at least a small portion of supplements to survive, but they have the ability to readapt to reduced growth conditions within $24 \mathrm{~h}$. Similar results were obtained in a study using cortisol [15]. We also observed a lower influence of dex in the presence of all growth factors, especially VEGF, indicating that growth factors play a major role on how dex can affect endothelial cells. This hypothesis was confirmed by the results obtained when HUVECs were grown in DM. Regarding TLS formation, we could show that the higher the concentration of dex, the more influenced each single component was e.g., building of nodes or junctions. The results in the present study clarify the immediate relation between the exogenous dex and its ability to inhibit the VEGF-induced TLS formation in endothelial cells, which has also been reported in another study [46]. This inhibition could be explained by the fact that dex decreases cell-cell contacts [15] and influences cell proliferation, which was also confirmed in our study (Figure S2). The dex-induced inhibition was VEGF-mediated at low concentrations, whereas higher concentrations seemed to be VEGF independent.

In conclusion, our results show that dex effects on cell viability and TLS formation of HUVECs depend on growth factors, especially on VEGF.

Gene expression analyses of CD31 on HUVECs maintained in mono-culture in different media confirmed that higher concentrations of dex have a high impact on angiogenesis and that growth factors play an important role in the process of angiogenesis. The statistically significant downregulation of CD31 gene expression after $100 \mu \mathrm{M}$ dex treatment for $24 \mathrm{~h}$ in Matrigel in HM1 medium indicated that the high concentration reduced the angiogenesis process in HUVECs. Interestingly, the exclusion of VEGF (HM1-V) led to no statistically significant downregulation of CD31 gene expression suggesting that VEGF was not in itself an important factor for the induction of angiogenesis.

$V E G F$ gene expression was not or only minimally influenced at any condition tested (Figure 3a). These results were unexpected, as it was reported that GCs inhibit the process of angiogenesis by inhibiting VEGF $[28,29,47,48]$. Nagashima et al. found that dex inhibited VEGF gene expression as a result of dex treatment [49]. Only one other study showed that dex did not influence VEGF gene expression of endothelial progenitor cells [50], confirming the findings in the present study with HUVECs.

Gene expression of the pro-inflammatory cytokine IL- 6 was influenced in some conditions tested. Only $100 \mu \mathrm{M}$ dex induced a significant upregulation of IL-6 gene expression (Figure 3b) compared to the untreated control when cells were seeded on normal plastic culture plates without VEGF in the medium (Figure 3b). Downregulation by dex was observed in HUVECs cultured in DM after 10 and $100 \mu \mathrm{M}$ dex treatment compared to the untreated control, which was also reported in previously published studies [21-23]. Normally, IL-6 gene is only activated during inflammation and dex decreases the production of IL-6 cytokines [21-23]. As we did not induce inflammatory conditions in this study, we did not expect an $I L-6$ upregulation under these normal conditions.

Gene expression of the anti-inflammatory cytokine $I L-10$ was either not regulated (DM-medium) or upregulated after 10 and $100 \mu \mathrm{M}$ dex compared to control (EBM-2 without GF). These results indicated that dex had the same impact on $I L-10$ expression in HUVECs as in monocytes [51]. Gene expression of the anti-inflammatory cytokine IL-10 
was (except $10 \mu \mathrm{M}$ dex in HM1 medium) not statistically significantly downregulated compared to the control and independent of VEGF (Figure 3a). IL-10 inhibits the production of pro-inflammatory cytokines, such as IL- 6 reducing the inflammation process under inflammatory conditions [52]. It has been demonstrated that dex increases the gene expression of IL-10 in monocytes under normal conditions [51]. However, we detected neither a significant downregulation nor significant expression changes of $I L-10$ under normal conditions or when VEGF was not in the medium. This indicates that this cytokine is not influenced in endothelial cells when treated with dex under normal conditions.

The significant downregulation of the GR after 10 as well as after $100 \mu \mathrm{M}$ dex addition, when cultured in EBM-2 without GF or in medium without VEGF, was also observed in our pervious study in primary human myotubes [33].

The concentration of $10 \mu \mathrm{M}$ did not alter HiF1 $\alpha$ expression, whereas $100 \mu \mathrm{M}$ significantly downregulated its expression (Figure 5a), indicating that high concentrations lead to the inhibition of HiF1 $\alpha$ resulting in the reduced expression of the GR, which has already been described in another study [36]. It also indicates that dex impairs the function of HiF1 $\alpha$, described by Elsby et al. [53], although others found that dex induced the repression of HiF1 $\alpha$ expression [37]. The gene expression of HiF1 $\alpha$ was only significantly downregulated after maintaining in HM1-V medium and the incubation with $10 \mu \mathrm{M}$ compared to the untreated control cells. These results suggest that the influence of dex on HiF1a gene expression was independent of VEGF under non hypoxic conditions. Other studies reported that dex induced the suppression of HiF1 $\alpha$ [37] and that dex suppressed the expression of the HiF1 target gene VEGF in HepG2 cells [36]. However, our results show that dex did not influence HiF1 $\alpha$ under normal conditions and HiF1 $\alpha$ remained continuously expressed, demonstrating that dex did not repress HiF1 $\alpha$ in endothelial cells under dex induced conditions and that this effect was independent of VEGF (Figure 3a).

Our findings indicate that the expression of HiF1 $\alpha$ depends on the GR. Similar findings were observed in HeLa cells [38]. They found that HiF1 $\alpha$-dependent gene expression is upregulated by GCs via the GR and that its activation is associated with HiF1 $\alpha$ upregulation.

In conclusion, the gene expression analyses confirm the findings that regulation by dex depends on the growth factor and cytokine environment of the cultured cells, whereas culture conditions regarding $2 \mathrm{D}$ or 3D play a minor role.

\subsection{Effects of Dex in a Co-Culture System of Human Endothelial Cells with Primary Myoblasts}

\subsubsection{Formation of Vessel-Like Structures in the Co-Culture}

To our knowledge, no co-culture models consisting of human endothelial cells and human primary myoblasts to analyze cell-cell interactions in regard to muscle regeneration or development of muscle atrophy exist. Therefore, we established a co-culture model of these cell types in different cell media and characterized it regarding angiogenesis, gene expression and proliferation. We observed a strong angiogenesis in the co-cultures independent from the media applied-even without applied growth factor, in particular, without VEGF (Figure 6). Our hypothesis is that this effect has been caused by a VEGF release from human primary myoblasts comparable to the release of VEGF described in murine myoblasts $[54,55]$. Our results indicate that by VEGF release of human myoblasts, the vascular development is regulated and induced in our co-culture system.

In co-culture, a clear and directed cell formation of HUVECs could be observed (Figure 6), which suggested the migration and differentiation of HUVECs due to the VEGF release by myoblasts (Figure 9). A similar cell formation of a capillary network has been described in murine myoblasts [56,57].

These results indicate an enhanced angiogenesis through maintaining HUVECs and myoblasts together even without additional growth factors, indicating a positive influence of myoblasts on HUVECs and angiogenesis.

To analyze the effect of dex on cell behavior and angiogenesis, the co-culture was incubated with 10 and $100 \mu \mathrm{M}$ dex for 48 and $96 \mathrm{~h}$. The results show that already low concentrations of dex affected the formation of bulges in HUVECs, including cell migration 
clearly indicating that dex had a higher influence on HUVECs than on the other cell types. The observations suggest that dex inhibited the process of angiogenesis similar to the process previously described for keratinocytes [28,29]. In the mentioned studies, the authors suggested that angiogenesis is impaired by dex inhibiting VEGF expression. This might be an explanation for the findings of the experiments using DM medium without growth factors in combination with dex. Although the medium contains no growth factors, HUVECs proliferated as VEGF is released by myoblasts. Our hypothesis is that dex caused a reduction of the VEGF-release, which resulted in a reduced microvessel density. Similar results have been obtained in a study with prostate cancer cells [27] and in a mono-culture of myoblasts [58].

\subsubsection{Dex Impairs Angiogenesis}

To further determine the effect of dex on both cell types in the co-culture, immunofluorescence analyzes were performed for MyHC or CD31 after treatment with 10 and $100 \mu \mathrm{M}$ dex. Both concentrations of dex did not influence the MyHC protein expression and did not inhibit the myotube formation in the established co-culture model. However, the formation of bulges, the building of a meshed network as well as angiogenesis and CD31 protein expression was decreased in HUVECs after the incubation with dex.

The results show that dex has different effects on different cell types. Dex inhibits angiogenesis by suppressing CD31 in mono- as well as in a co-culture with human primary myoblasts, whereas the expression of myogenic markers is not influenced by dex. Our hypothesis is that dex influences angiogenesis and thereby indirectly muscle regeneration or the development of muscle atrophy after dex treatment. One possible mechanism could be the decreased VEGF release in the co-culture after dex treatment (Figure 9), resulting in an inhibition of angiogenesis and of the formation of bulge like structures from HUVECs.

These results are confirmed by gene expression analyses: dex reduced CD31 and $V E G F$ gene expression, whereas the myogenic transcription factors $M y o D$ and $M y o G$ were expressed significantly higher after dex treatment, indicating that dex simultaneously had suppressing effects on endothelial cells and enhancing effects on myoblast gene expression. These enhancing effects of dex on myogenic expression were also observed in our previous study in the mono-culture of primary human myoblasts [33]. A significant downregulation of HiF1 $\alpha$ gene expression was detected with both dex concentrations, indicating that dex had the potential to repress its expression and function in the co-culture and as a consequence inhibiting VEGF expression. These results show that dex has a major affinity to endothelial cells and thus influences gene expression and as a consequence, a function of these cells.

mRNA expression of GR is not significantly downregulated by dex in the co-culture but in mono-culture of HUVECs it is downregulated after treatment with $10 \mu \mathrm{M}$ dex. This speaks to a different regulation of GR by dex in different cells, which has also been described in mouse or rat myotubes [59]. Others described that glucocorticoid treatment did not result in reduced GR mRNA and protein levels, but showed that upon dex treatment, GR is activated and translocates to the nucleus in C2C12 cells [60,61]. The protein expression analyses of CD31 (Figure 8) indicated repressing properties of dex on its expression and could function as a negative response element of the GR (nRE) under normal conditions. The two cell types stimulated each other to promote angiogenesis or myogenesis, showing that these two biological processes are coupled, which has also been described in another context [62].

In this study, we are the first to perform co-culture experiments to demonstrate cellular interactions of human endothelial cells and primary myoblasts under dex influence. This model represents an in vitro model for muscle regeneration and/or development of muscle atrophy, and demonstrates different effects of dex on different cells cultured in mono- or co-culture models. 


\section{Materials and Methods}

\subsection{Reagents}

Endothelial cell basal medium (EBM-2), EGM ${ }^{\mathrm{TM}}-2$ BulletKit ${ }^{\mathrm{TM}}$ were purchased from Lonza (Wokingham, UK); $\mathrm{EGM}^{\mathrm{TM}}-2$ BulletKit ${ }^{\mathrm{TM}}$ : ascorbic acid, hydrocortisone, heparin, gentamicin/amphotericin B, VEGF, epidermal growth factor (EGF), insulin-like growth factor (IGF), fibroblast growth factor (FGF), Dulbecco's modified Eagle medium (DMEM/F-12) (1:1) + GlutaMAX and Penicillin Streptomycin, 10,000 U/mL Penicillin; 10,000 $\mu \mathrm{g} / \mathrm{mL}$ Streptomycin were purchased from Gibco ${ }^{\circledR}$ Life Technologies(Grand Island, NE, USA). Fetal Calf (FCS) and Horse serum (HS) were purchased from Biochrom GmbH (Berlin, Germany) and bFGF from BPS Bioscience (San Diego, CA, USA). RU-486 (Mifepristone) was purchased from MyBioSource (San Diego, CA, USA).

\subsection{Cell Culture}

HUVECs (primary human umbilical vein cells), purchased from PromoCell (Heidelberg, Germany) were maintained in endothelial cell basal medium (EBM-2) and the provided supplements of the $\mathrm{EGM}^{\mathrm{TM}}-2$ BulletKit ${ }^{\mathrm{TM}}$ (Table 1, HM1) at $37^{\circ} \mathrm{C}$ in a humidified atmosphere containing $5 \% \mathrm{CO}_{2}$. The medium was changed every second day. The isolation as well as characterization and differentiation of primary human myoblasts were previously described and published [33]. Muscle tissue was cut into small pieces followed by collagenase type II (470 U/DMEM-F-12, Worthington Biochemical Corporation, Lakewood, CO, USA) and Trypsin/EDTA (0.025\%/0.02\%, Biochrom GmbH, Berlin, Germany) treatment at $37^{\circ} \mathrm{C}$ in a water bath. Cell suspensions were seeded in collagen coated culture flasks and incubated at $37^{\circ} \mathrm{C}$ and $5 \% \mathrm{CO}_{2}$. The medium (MM1) was changed every second day. Cell differentiation was induced by serum reduction with differentiation medium (DM). Cell media were supplemented with antibiotics (1\% Pen.Strep). The use of residual material was approved by the ethics committee of the Landesärztekammer Rheinland-Pfalz in accordance with the principles expressed in the Declaration of Helsinki and the ICH Guidelines for GCP. All patients provided written consent.

Myoblast purity was about $80 \%$ after isolation, which was proved by FACS analyses for non-muscle cells (e.g., CD45) and immunofluorescence stainings for myoblasts (Myf5, MyoD, NCAM, MyHC) and fibroblasts (fibroblast surface protein, $\alpha$-SMA). We used the C2C12 cell line as control cells for the immunofluorescence analyses (DSMZ, Braunschweig, Germany). We also proved that isolated cells were able to differentiate into myotubes confirming the myoblastic phenotype of our isolated cells [33,63-65].

\subsection{Cell Viability and Proliferation Assay}

To evaluate the viability and proliferation of endothelial cells after dex treatment, the alamarBlue ${ }^{\circledR}$ assay was performed (Gibco ${ }^{\circledR}$ Invitrogen ${ }^{\mathrm{TM}}$ Life Technologies, Carlsbad, CA, USA). Cells $\left(1.0 \times 10^{4}\right)$ were seeded in a 24-well plate and incubated in HM1. After $24 \mathrm{~h}$ medium was refreshed and cells were incubated with or without dex for 24,48 , and $72 \mathrm{~h}$. Control cells were incubated without dex. Measurements were repeated three times $(n=3)$ and analyzed using the GloMax ${ }^{\circledR}$ Multidetection System (Promega, Madison, WI, USA) (Ex: 525 nm; Em: 580-649 nm).

In all experiments, we used dex concentrations of 0,10 , and $100 \mu \mathrm{M}$ as described in similar studies with murine $\mathrm{C} 2 \mathrm{C} 12$ cells $[44,45]$. To show the specificity of dex, viability experiments were performed with the inhibitor RU-496 $(10 \mu \mathrm{M})$.

\subsection{Tube-Like Structure (TLS) Assay}

HUVECs $\left(5.0 \times 10^{4}\right.$ cells/well) were re-suspended in Matrigel (BD Biosciences, New Jersey, NJ, USA), seeded in a 96-well plate and incubated at $37^{\circ} \mathrm{C}$ for 30 mins to allow polymerization of the gel. After that, different media compositions with 10 and $100 \mu \mathrm{M}$ dex were added to cells for further incubation. The TLS were photographed from the same position at the center of each well after $24 \mathrm{~h}$ and analyzed using the Angiogenesis analyzer 
software in ImageJ. Images used as example to visualize this assay (not the original) were added in the Supplementary Materials.

\subsection{Evaluation of a Co-Culture System of Primary Human Myoblasts and Endothelial Cells}

Both cell types were seeded in collagen coated tissue culture plates at the same ratio (1:1) and incubated until they reached $80 \%$ confluence (Figure 11). The co-culture growth medium (HM1/MM1) contained a 1:1 mixture of both growth media (Table 2). For induction of angiogenesis or myogenesis and to test cell behavior and their cell interactions as a co-culture, two different media compositions were used: first, the HM1/DM of HUVECs growth medium (HM1) and the differentiation medium of myoblasts (DM); and as a second, only the differentiation medium (DM) of myoblasts. Cells were incubated with both media for 5 days and analyzed.

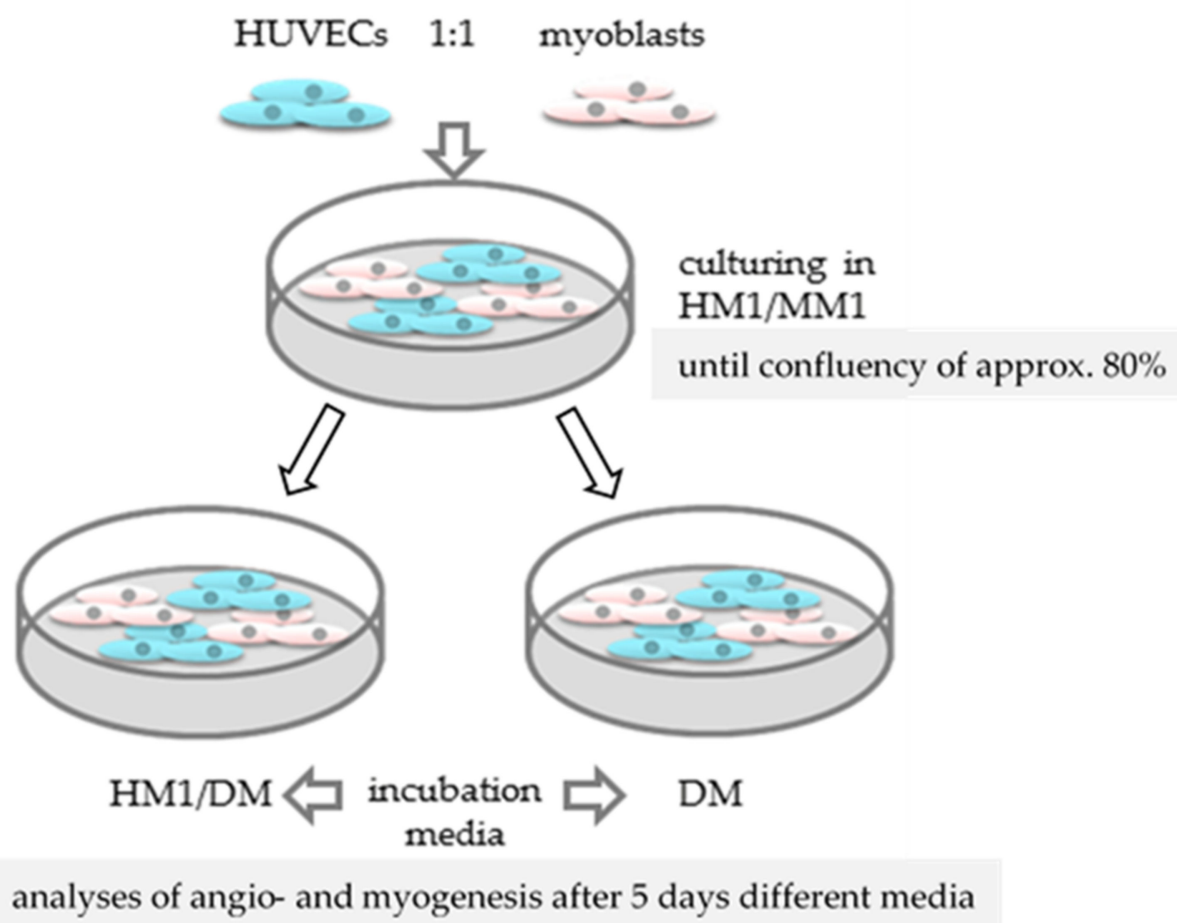

Figure 11. Experimental design of the co-culture evaluation with primary human myoblasts and HUVECs.

\subsection{Lentiviral Transduction}

To allow analysis by fluorescent microscopy, cells were transduced with a lentiviral vector encoding the mCherry protein. Vector supernatants were collected and concentrated from transfected 293T producer cells as previously described [66]. For lentiviral transduction, $2 \times 10^{4}$ HUVECs were seeded in 24-well plates. After $24 \mathrm{~h}$, the medium was replaced by medium containing $5 \mu \mathrm{g} / \mathrm{mL}$ protaminsulfate (Sigma-Aldrich ${ }^{\circledR} \mathrm{GmbH}$, St. Louis, MO, USA). Subsequently, $20 \mu \mathrm{L}$ of a 1:10 in medium diluted virus suspension was pipetted into each well and incubated for $6 \mathrm{~h}$. Flow cytometry analyses one week after transduction confirmed a transduction efficiency of $90 \%$.

\subsection{Immunofluorescence}

To detect angiogenesis or myogenesis in the co-culture, cells were stained with the specific antibody MyHC for myotubes (myogenesis) and CD31 for HUVECs (angiogenesis) and immunofluorescence analyses were performed.

After washes with PBS (Gibco ${ }^{\circledR}$ Invitrogen ${ }^{\mathrm{TM}}$ Life Technologies, Carlsbad, CA, USA), cells were fixed and permeabilized with methanol for $20 \mathrm{~min}$ followed again by washes with 
PBS. The following primary antibodies were used and incubated over night at $4{ }^{\circ} \mathrm{C}$. Skeletal Muscle MyHC (F59: sc-32732, 1:200, Santa Cruz Biotechnology, Dallas, TX, USA) and CD31 (ab28364, 1:50, Abcam, Cambridge, GB). After washes with BSA/PBS cells were stained with the secondary antibody Alexa Fluor ${ }^{\circledR} 488$ (A11001 and A11008, 1:200, Invitrogen ${ }^{\mathrm{TM}}$ Life Technologies, Carlsbad, CA, USA) for $1 \mathrm{~h}$ in the dark at room temperature. Nuclei staining was performed with Hoechst dye (Hoechst dye 334565, Sigma-Aldrich ${ }^{\circledR} \mathrm{GmbH}$, St. Louis, MO, USA) before detection using the EVOS ${ }^{\circledR}$ Digital Inverted Microscope (EVOS fl, Life Technologies, Carlsbad, CA, USA). Experiments were performed three times.

\subsection{Quantitative Real-Time Polymerase Chain Reaction ( $q P C R$ )}

Total RNA isolation from HUVECs in Matrigel was performed using TRIzol reagent (Invitrogen $^{\mathrm{TM}}$, Life Technologies, Paisley, UK). RNA from all other cell experiments was isolated with the RNA isolation kit (peqGold, total RNA kit, PEQLAB Biotechnology GmbH, Erlangen, Germany) according to manufacturer instructions followed by quantification using UV spectroscopy.

$1 \mu \mathrm{g}$ of total RNA was reverse transcribed into cDNA using dNTPs (4you 4 dNTPs mix (10 mM), BIORON GmbH, Ludwigshafen, Germany), random primers (Promega, Madison, WI, USA) and MuLV RT (M-MuLV Reverse Transcriptase, M0253S New England Biolabs, Ipswich, USA) according to manufacter instructions.

For gene expression analysis, cDNA template underwent PCR amplification (40 cycles) using the Biozym Blue S'Green Master Mix (Biozym Scientific GmbH, Hessisch Oldendorf, Germany) and sequence specific primers (Primer sequences are listed in Table 3) for human CD31, VEGF, IL-6, -10, HiF1 $\alpha, M y o D$, and MyoG. GAPDH was used to normalize gene expression. Sample amplification was performed with the qTower3 (Jena Analytik, Jena, Germany). An initial denaturation step at $95^{\circ} \mathrm{C}$ for $2 \mathrm{~min}$, denaturation, and enzyme activation at $95^{\circ} \mathrm{C}$ for $5 \mathrm{sec}$ followed by $60^{\circ} \mathrm{C}$ for $30 \mathrm{sec}$ for annealing and extension were performed. Results were calculated using the $2^{-\Delta \Delta} \mathrm{Ct}$ method [55]; they presented the expression levels of cells relative to gene expression of untreated cells.

Table 3. Primer sequences for qPCR analysis (Eurofins Genomics, Ebersberg, Germany).

\begin{tabular}{cc}
\hline Primer & Sequence \\
\hline GAPDH & FW: cgaccactttgtcaagctca \\
Acc.\# M33197 & RV: aggggagattcagtgtggtg \\
CD31 & FW: cattggcgtgttgggaagaa \\
Acc.\# NM_000442 & RV: gctcatgtttgcctagctcc \\
VEGF & FW: agatgagcttcctacagcacaac \\
Acc.\# M32977 & RV: aggacttataccgggatttcttg \\
IL-6 & FW: cacagacagccactcacctc \\
Acc.\# NM_000600 & RV: cctcaaactccaaaagacca \\
IL-10 & FW: cgtggagcaggtgaagaatg \\
Acc.\# NM_000572 & RV: atagaaatgggggttgaggt \\
HiF1 & FW: gaaaacttggcaaccttgga \\
Acc.\# NM_001243084 & RV: atctccgtcctcaacctct \\
GR & FW: caaatcagcctttcctcggg \\
Acc.\# AB307716 & RV: ctggccettcaaatgttgct \\
MyoD & FW: ggggctaggttcagctttct \\
Acc.\# X56677.1 & RV: gctctggcaaagcaactctt \\
MyoG & FW: gccagactatcccttcctc \\
Acc.\# NM_002479.5 & RV: gaggccgcgttatgataaaa \\
\hline
\end{tabular}

\subsection{Enzyme-Linked Immunosorbent Assay (ELISA)}

To test if our primary myoblasts secreted any angiogenesis induced growth factors, VEGF ELISA was performed using the human VEGF, DuoSet ${ }^{\circledR}$ (Elisa Development System, R\&D systems ${ }^{\mathrm{TM}}$ Inc., Minneapolis, MN, USA) from the co-culture without any added growth factors $24,48,72$, and $96 \mathrm{~h}$ after switching the medium from growth to differentiation medium (DM). Experiments were repeated three times and measurements were 
performed in duplicates. Absorbance was measured at $450 \mathrm{~nm}$ using a Dynex microplate reader (DYNEX TECHNOLOGIES, Buštěhrad, Czech Republic).

\subsection{Statistical Analysis}

Statistical analyses were performed using SPSS (IBM ${ }^{\circledR} \mathrm{GmbH}$, Ehningen, Germany). The results are presented as medians and quartiles or as mean \pm standard deviation. Measurements were carried out in duplicates or triplicates. Experiments were independently repeated three times. Normally distributed data were analyzed by one-way ANOVA and pairwise comparisons were conducted post hoc test. Non-normally distributed data were evaluated with the Kruskal-Wallis test. For pairwise comparisons, the Mann-Whitney-U test was used and $p$-values $<0.05$ were considered statistically significant $\left({ }^{*} p<0.05\right)$.

\section{Conclusions}

In the present study, we investigated the effect of the GC dex on endothelial cells in a mono-culture and in a co-culture with myoblasts under different growth conditions. To our knowledge, we are the first to establish and evaluate a co-culture of primary human myoblasts and HUVECs, to analyze their growth behavior and the impact of dex on both cell types with regard to development of muscle atrophy.

We found that dex had different effects on different cell types in mono- and in a co-culture system. We observed a cell type specific affinity of dex to HUVECs and the repression of angiogenic genes and proteins, and as a result repressed angiogenesis in a co-culture. Furthermore, dex impaired VEGF release of myoblasts and as a consequence, angiogenesis. These results indicate that dex affects angiogenesis via inhibition of VEGF release at least in myoblasts, which could be responsible not only for the development of muscle atrophy after dex administration, but also for inhibition muscle regeneration in combination with vascular damage.

Supplementary Materials: The following are available online at https:/ /www.mdpi.com/article/10 $.3390 / \mathrm{ijms} 22157986 / \mathrm{s} 1$.

Author Contributions: Conceptualization, E.K.L., U.R.; data curation, E.K.L.; methodology, E.K.L.; project administration, P.M.R. and P.D.; resources, P.M.R. and P.D.; supervision, U.R.; writingoriginal draft preparation, E.K.L.; writing—review and editing, U.R., P.M.R., P.D., and E.K.L. All authors have read and agreed to the published version of the manuscript.

Funding: This research received no external funding.

Institutional Review Board Statement: The study was conducted according to the guidelines of the Declaration of Helsinki, and approved by the Ethics Committee of the Landesärztekammer Rheinland-Pfalz. All patients provided written consent.

Data Availability Statement: The datasets used and/or analysed during the current study are available from the corresponding author on reasonable request.

Acknowledgments: We thank Stefan Stein (Georg-Speyer-Haus, Frankfurt, Germany) for kindly providing the mCherry vector that we used in the experiments. The results described in this article are part of the doctoral thesis of E.K.L. at the University Medical Center Mainz/Johannes Gutenberg University Mainz.

Conflicts of Interest: The authors declare no conflict of interest.

\section{References}

1. Liekens, S.; De Clercq, E.; Neyts, J. Angiogenesis: Regulators and Clinical Applications. Biochem. Pharmacol. 2001, 61, $253-270$. [CrossRef]

2. Kerbel, R.S. Tumor Angiogenesis. N. Engl. J. Med. 2008, 358, 2039-2049. [CrossRef]

3. Chung, A.S.; Ferrara, N. Developmental and Pathological Angiogenesis. Annu. Rev. Cell Dev. Biol. 2011, 27, 563-584. [CrossRef] [PubMed]

4. Carmeliet, P.; Jain, R.K. Molecular Mechanisms and Clinical Applications of Angiogenesis. Nat. Cell Biol. 2011, 473, $298-307$. [CrossRef] 
5. Potente, M.; Gerhardt, H.; Carmeliet, P. Basic and Therapeutic Aspects of Angiogenesis. Cell 2011, 146, 873-887. [CrossRef]

6. Coultas, L.; Chawengsaksophak, K.; Rossant, J. Endothelial Cells and VEGF in Vascular Development. Nat. Cell Biol. 2005, 438, 937-945. [CrossRef]

7. Ortega, S.; Ittmann, M.; Tsang, S.H.; Ehrlich, M.; Basilico, C. Neuronal Defects and Delayed Wound Healing in Mice Lacking Fibroblast Growth Factor 2. Proc. Natl. Acad. Sci. USA 1998, 95, 5672-5677. [CrossRef]

8. Nissen, N.N.; Polverini, P.J.; Koch, A.E.; Volin, M.V.; Gamelli, R.L.; DiPietro, L.A. Vascular Endothelial Growth Factor Mediates Angiogenic Activity During the Proliferative Phase of Wound Healing. Am. J. Pathol. 1998, 152, 1445-1452. [PubMed]

9. Pober, J.S.; Sessa, W. Inflammation and the Blood Microvascular System. Cold Spring Harb. Perspect. Biol. 2015, 7, a016345. [CrossRef] [PubMed]

10. Gerdes, N.; Sukhova, G.K.; Libby, P.; Reynolds, R.S.; Young, J.L.; Schönbeck, U. Expression of Interleukin (IL)-18 and Functional IL-18 Receptor on Human Vascular Endothelial Cells, Smooth Muscle Cells, and Macrophages. J. Exp. Med. 2002, 195, $245-257$. [CrossRef]

11. Knipe, L.; Meli, A.; Hewlett, L.; Bierings, R.; Dempster, J.; Skehel, P.; Hannah, M.J.; Carter, T. A Revised Model for the Secretion of TPA and Cytokines from Cultured Endothelial Cells. Blood 2010, 116, 2183-2191. [CrossRef]

12. Mai, J.; Nanayakkara, G.; Lopez-Pastrana, J.; Li, X.; Li, Y.-F.; Wang, X.; Song, A.; Virtue, A.; Shao, Y.; Shan, H.; et al. Interleukin-17A Promotes Aortic Endothelial Cell Activation via Transcriptionally and Post-Translationally Activating p38 Mitogen-Activated Protein Kinase (MAPK) Pathway. J. Biol. Chem. 2016, 291, 4939-4954. [CrossRef]

13. Chung, A.S.; Lee, J.; Ferrara, N. Targeting the Tumour Vasculature: Insights from Physiological Angiogenesis. Nat. Rev. Cancer 2010, 10, 505-514. [CrossRef] [PubMed]

14. Matsumoto, T.; Claesson-Welsh, L. VEGF Receptor Signal Transduction. Sci. STKE 2001, 112, re21. [CrossRef]

15. Logie, J.J.; Ali, S.; Marshall, K.M.; Heck, M.M.S.; Walker, B.R.; Hadoke, P.W.F. Glucocorticoid-Mediated Inhibition of Angiogenic Changes in Human Endothelial Cells Is Not Caused by Reductions in Cell Proliferation or Migration. PLoS ONE 2010, 5, e14476. [CrossRef]

16. Hoeben, A.; Landuyt, B.; Highley, M.S.; Wildiers, H.; Van Oosterom, A.T.; De Bruijn, E.A. Vascular Endothelial Growth Factor and Angiogenesis. Pharmacol. Rev. 2004, 56, 549-580. [CrossRef] [PubMed]

17. Olsson, A.-K.; Dimberg, A.; Kreuger, J.; Claesson-Welsh, L. VEGF Receptor Signalling? In Control of Vascular Function. Nat. Rev. Mol. Cell Biol. 2006, 7, 359-371. [CrossRef] [PubMed]

18. Germani, A.; Di Carlo, A.; Mangoni, A.; Straino, S.; Giacinti, C.; Turrini, P.; Biglioli, P.; Capogrossi, M.C. Vascular Endothelial Growth Factor Modulates Skeletal Myoblast Function. Am. J. Pathol. 2003, 163, 1417-1428. [CrossRef]

19. Joos, G.F.; Brusselle, G.; Van Hoecke, H.; Van Cauwenberge, P.; Bousquet, J.; Pauwels, R.A. Positioning of Glucocorticosteroids in Asthma and Allergic Rhinitis Guidelines (Versus Other Therapies). Immunol. Allergy Clin. N. Am. 2005, 25, 597-612. [CrossRef]

20. Schäcke, H.; Döcke, W.-D.; Asadullah, K. Mechanisms Involved in the Side Effects of Glucocorticoids. Pharmacol. Ther. 2002, 96, 23-43. [CrossRef]

21. Shi, J.-X.; Li, J.-S.; Hu, R.; Shi, Y.; Su, X.; Guo, X.-J.; Li, X.-M. Tristetraprolin Is Involved in the Glucocorticoid-Mediated Interleukin 8 Repression. Int. Immunopharmacol. 2014, 22, 480-485. [CrossRef] [PubMed]

22. You, Q.-H.; Zhang, D.; Niu, C.-C.; Zhu, Z.-M.; Wang, N.; Yue, Y.; Sun, G.-Y. Expression of IL-17A and IL-17F in LipopolysaccharideInduced Acute Lung Injury and the Counteraction of Anisodamine or Methylprednisolone. Cytokine 2014, 66, 78-86. [CrossRef] [PubMed]

23. Zakkar, M.; Le, A.L.; Chaudhury, H.; Ruud, O.; Punjabi, P.P.; Anderson, J.R.; Mullholand, J.W.; Clements, A.T.; Krams, R.; Foin, N.; et al. Dexamethasone Arterializes Venous Endothelial Cells by Inducing Mitogen-Activated Protein Kinase Phosphatase-1: A Novel Antiinflammatory Treatment for Vein grafts? Circulation 2011, 123, 524-532. [CrossRef]

24. Gelati, M.; Corsini, E.; De Rossi, M.; Masini, L.; Bernardi, G.; Massa, G.; Boiardi, A.; Salmaggi, A. Methylprednisolone Acts on Peripheral Blood Mononuclear Cells and Endothelium in Inhibiting Migration Phenomena in Patients With Multiple Sclerosis. Arch. Neurol. 2002, 59, 774-780. [CrossRef]

25. Vandevyver, S.; Dejager, L.; Tuckermann, J.; Libert, C. New Insights into the Anti-Inflammatory Mechanisms of Glucocorticoids: An Emerging Role for Glucocorticoid-Receptor-Mediated Transactivation. Endocrinology 2013, 154, 993-1007. [CrossRef] [PubMed]

26. Simoncini, T.; Maffei, S.; Basta, G.; Barsacchi, G.; Genazzani, A.R.; Liao, J.K.; De Caterina, R. Estrogens and Glucocorticoids Inhibit Endothelial Vascular Cell Adhesion Molecule-1 Expression by Different Transcriptional Mechanisms. Circ. Res. 2000, 87, 19-25. [CrossRef]

27. Yano, A.; Fujii, Y.; Iwai, A.; Kageyama, Y.; Kihara, K. Glucocorticoids Suppress Tumor Angiogenesis and In Vivo Growth of Prostate Cancer Cells. Clin. Cancer Res. 2006, 12, 3003-3009. [CrossRef]

28. Gille, J.; Reisinger, K.; Westphal-Varghese, B.; Kaufmann, R. Decreased MRNA Stability As a Mechanism of GlucocorticoidMediated Inhibition of Vascular Endothelial Growth Factor Gene Expression by Cultured Keratinocytes. J. Investig. Dermatol. 2001, 117, 1581-1587. [CrossRef]

29. Pufe, T.; Scholz-Ahrens, K.E.; Franke, A.T.M.; Petersen, W.; Mentlein, R.; Varoga, D.; Tillmann, B.; Schrezenmeir, J.; Glüer, C.C. The Role of Vascular Endothelial Growth Factor in Glucocorticoid-Induced Bone Loss: Evaluation in a Minipig Model. Bone 2003, 33, 869-876. [CrossRef]

30. Hasselgren, P.-O. Glucocorticoids and Muscle Catabolism. Curr. Opin. Clin. Nutr. Metab. Care 1999, 2, 201-205. [CrossRef] 
31. Annane, D. What Is the Evidence for Harm of Neuromuscular Blockade and Corticosteroid Use in the Intensive Care Unit? Semin. Respir. Crit. Care Med. 2016, 37, 51-56. [CrossRef]

32. Hermans, G.; Berghe, G.V.D. Clinical Review: Intensive Care Unit Acquired Weakness. Crit. Care 2015, 19, 1-9. [CrossRef]

33. Langendorf, E.K.; Rommens, P.M.; Drees, P.; Mattyasovszky, S.G.; Ritz, U. Detecting the Effects of the Glucocorticoid Dexamethasone on Primary Human Skeletal Muscle Cells_Differences to the Murine Cell Line. Int. J. Mol. Sci. 2020, 21, 2497. [CrossRef] [PubMed]

34. Griffiths, J.R.; McSheehy, P.M.J.; Robinson, S.P.; Troy, H.; Chung, Y.-L.; Leek, R.D.; Williams, K.J.; Stratford, I.J.; Harris, A.L.; Stubbs, M. Metabolic Changes Detected by in Vivo Magnetic Resonance Studies of HEPA-1 Wild-Type Tumors and Tumors Deficient in Hypoxia-Inducible Factor-1beta (HIF-1beta): Evidence of an Anabolic Role for the HIF-1 Pathway. Cancer Res. 2002, 62, 688-695. [PubMed]

35. Iyer, N.V.; Kotch, L.E.; Agani, F.; Leung, S.W.; Laughner, E.; Wenger, R.H.; Gassmann, M.; Gearhart, J.D.; Lawler, A.M.; Yu, A.Y.; et al. Cellular and Developmental Control of O2 Homeostasis by Hypoxia-Inducible Factor 1alpha. Genes Dev. 1998, 12, 149-162. [CrossRef] [PubMed]

36. Wagner, A.; Huck, G.; Stiehl, D.; Jelkmann, W.; Hellwig-Bürgel, T. Dexamethasone Impairs Hypoxia-Inducible Factor-1 Function. Biochem. Biophys. Res. Commun. 2008, 372, 336-340. [CrossRef]

37. Lim, W.; Park, C.; Shim, M.K.; Lee, Y.H.; Lee, Y.M.; Lee, Y. Glucocorticoids Suppress Hypoxia-Induced COX-2 and Hypoxia Inducible Factor-1alpha Expression through the Induction of Glucocorticoid-Induced Leucine Zipper. Br. J. Pharmacol. 2014, 171, 735-745. [CrossRef]

38. Kodama, T.; Shimizu, N.; Yoshikawa, N.; Makino, Y.; Ouchida, R.; Okamoto, K.; Hisada, T.; Nakamura, H.; Morimoto, C.; Tanaka, H. Role of the Glucocorticoid Receptor for Regulation of Hypoxia-Dependent Gene Expression. J. Biol. Chem. 2003, 278, 33384-33391. [CrossRef]

39. De Bosscher, K.; Berghe, W.V.; Haegeman, G. The Interplay Between the Glucocorticoid Receptor and Nuclear Factor-KappaB or Activator Protein-1: Molecular Mechanisms for Gene Repression. Endocr. Rev. 2003, 24, 488-522. [CrossRef]

40. Han, D.-S.; Yang, W.-S.; Kao, T.-W. Dexamethasone Treatment at the Myoblast Stage Enhanced C2C12 Myocyte Differentiation. Int. J. Med. Sci. 2017, 14, 434-443. [CrossRef]

41. Young, H.Y.S.S.; Woo, J.J. The Effects of Trapa Japonica Fructus Protecs Dexamethasone Induced Muscle Atrophy in C2C12 Myotubes. Int. J. Food Sci. Nutr. Res. 2019, 2, 9.

42. Wang, R.; Jiao, H.; Zhao, J.; Wang, X.; Lin, H. Glucocorticoids Enhance Muscle Proteolysis through a Myostatin-Dependent Pathway at the Early Stage. PLoS ONE 2016, 11, e0156225. [CrossRef]

43. Desler, M.M.; Jones, S.J.; Smith, C.W.; Woods, T.L. Effects of Dexamethasone and Anabolic Agents on Proliferation and Protein Synthesis and Degradation in C2C12 Myogenic Cells. J. Anim. Sci. 1996, 74, 1265-1273. [CrossRef] [PubMed]

44. Aguilar-Agon, K.W.; Capel, A.J.; Fleming, J.W.; Player, D.J.; Martin, N.R.W.; Lewis, M.P. Mechanical Loading of Tissue Engineered Skeletal Muscle Prevents Dexamethasone Induced Myotube Atrophy. J. Muscle Res. Cell Motil. 2020, 1-11. [CrossRef]

45. Shimizu, K.; Genma, R.; Gotou, Y.; Nagasaka, S.; Honda, H. Three-Dimensional Culture Model of Skeletal Muscle Tissue With Atrophy Induced by Dexamethasone. Bioengineering 2017, 4, 56. [CrossRef] [PubMed]

46. Folkman, J.; Langer, R.; Linhardt, R.; Haudenschild, C.; Taylor, S. Angiogenesis Inhibition and Tumor Regression Caused by Heparin or a Heparin Fragment in the Presence of Cortisone. Science 1983, 221, 719-725. [CrossRef]

47. Nauck, M.; Karakiulakis, G.; Perruchoud, A.P.; Papakonstantinou, E.; Roth, M. Corticosteroids Inhibit the Expression of the Vascular Endothelial Growth Factor Gene in Human Vascular Smooth Muscle Cells. Eur. J. Pharmacol. 1998, 341, $309-315$. [CrossRef]

48. Wen, F.-Q.; Liu, X.; Manda, W.; Terasaki, Y.; Kobayashi, T.; Abe, S.; Fang, Q.; Ertl, R.; Manouilova, L.; Rennard, S.I. TH2 CytokineEnhanced and TGF-Beta-Enhanced Vascular Endothelial Growth Factor Production by Cultured Human Airway Smooth Muscle Cells Is Attenuated by IFN-Gamma and Corticosteroids. J. Allergy Clin. Immunol. 2003, 111, 1307-1318. [CrossRef]

49. Nagashima, M.; Yoshino, S.; Aono, H.; Takai, M.; Sasano, M. Inhibitory Effects of Anti-Rheumatic Drugs on Vascular Endothelial Growth Factor in Cultured Rheumatoid Synovial Cells. Clin. Exp. Immunol. 1999, 116, 360-365. [CrossRef]

50. Carolina, E.; Kato, T.; Khanh, V.C.; Moriguchi, K.; Yamashita, T.; Takeuchi, K.; Hamada, H.; Ohneda, O. Glucocorticoid Impaired the Wound Healing Ability of Endothelial Progenitor Cells by Reducing the Expression of CXCR4 in the PGE2 Pathway. Front. Med. 2018, 5, 276. [CrossRef] [PubMed]

51. Mozo, L.; Suarez-Diaz, A.M.; Gutierrez, C. Glucocorticoids up-Regulate Constitutive Interleukin-10 Production by Human Monocytes. Clin. Exp. Allergy 2004, 34, 406-412. [CrossRef] [PubMed]

52. Malefyt, R.D.W.; Abrams, J.; Bennett, B.; Figdor, C.; De Vries, J.E. Interleukin 10(IL-10) Inhibits Cytokine Synthesis by Human Monocytes: An Autoregulatory Role of IL-10 Produced by Monocytes. J. Exp. Med. 1991, 174, 1209-1220. [CrossRef]

53. Elsby, L.M.; Donn, R.; Alourfi, Z.; Green, L.M.; Beaulieu, E.; Ray, D.W. Hypoxia and Glucocorticoid Signaling Converge to Regulate Macrophage Migration Inhibitory Factor Gene Expression. Arthritis Rheum. 2009, 60, 2220-2231. [CrossRef]

54. Von Degenfeld, G.; Banfi, A.; Springer, M.L.; Wagner, R.A.; Jacobi, J.; Ozawa, C.R.; Merchant, M.J.; Cooke, J.; Blau, H.M. Microenvironmental VEGF Distribution Is Critical for Stable and Functional Vessel Growth in Ischemia. FASEB J. 2006, 20, 2657-2659. [CrossRef] [PubMed] 
55. Ozawa, C.R.; Banfi, A.; Glazer, N.; Thurston, G.; Springer, M.L.; Kraft, P.E.; McDonald, D.M.; Blau, H.M. Microenvironmental VEGF Concentration, Not Total Dose, Determines a Threshold Between Normal and Aberrant Angiogenesis. J. Clin. Investig. 2004, 113, 516-527. [CrossRef] [PubMed]

56. Marsano, A.; Maidhof, R.; Luo, J.; Fujikara, K.; Konofagou, E.E.; Banfi, A.; Vunjak-Novakovic, G. The Effect of Controlled Expression of VEGF by Transduced Myoblasts in a Cardiac Patch on Vascularization in a Mouse Model of Myocardial Infarction. Biomaterials 2013, 34, 393-401. [CrossRef]

57. Wang, J.; Morita, I.; Onodera, M.; Murota, S.-I. Induction of KDR Expression in Bovine Arterial Endothelial Cells by Thrombin: Involvement of Nitric Oxide. J. Cell. Physiol. 2002, 190, 238-250. [CrossRef]

58. Nagamori, E.; Ngo, T.X.; Takezawa, Y.; Saito, A.; Sawa, Y.; Shimizu, T.; Okano, T.; Taya, M.; Kino-Oka, M. Network Formation through Active Migration of Human Vascular Endothelial Cells in a Multilayered Skeletal Myoblast Sheet. Biomaterials 2013, 34, 662-668. [CrossRef]

59. Menconi, M.; Gonnella, P.; Petkova, V.; Lecker, S.; Hasselgren, P.-O. Dexamethasone and Corticosterone Induce Similar, But Not Identical, Muscle Wasting Responses in Cultured L6 and C2C12 Myotubes. J. Cell. Biochem. 2008, 105, 353-364. [CrossRef]

60. Vujčić, M.T.; Velickovic, N.; Ruzdijic, S. Dexamethasone Treatment Affects Nuclear Glucocorticoid Receptor and Glucocorticoid Response Element Binding Activity in Liver of Rats (Rattus Norvegicus) During Aging. Comp. Biochem. Physiol. Part B Biochem. Mol. Biol. 2007, 148, 463-469. [CrossRef]

61. Erdeljan, P.; Andrews, M.H.; Macdonald, J.F.; Matthews, S.G. Glucocorticoids and Serotonin Alter Glucocorticoid Receptor MRNA Levels in Fetal Guinea-Pig Hippocampal Neurons, in Vitro. Reprod. Fertil. Dev. 2005, 17, 743-749. [CrossRef] [PubMed]

62. Latroche, C.; Weiss-Gayet, M.; Muller, L.; Gitiaux, C.; Leblanc, P.; Liot, S.; Ben-Larbi, S.; Abou-Khalil, R.; Verger, N.; Bardot, P.; et al. Coupling Between Myogenesis and Angiogenesis During Skeletal Muscle Regeneration Is Stimulated by Restorative Macrophages. Stem Cell Rep. 2017, 9, 2018-2033. [CrossRef] [PubMed]

63. Langendorf, E.K.; Klein, A.; Drees, P.; Rommens, P.M.; Mattyasovszky, S.G.; Ritz, U. Exposure to Radial Extracorporeal Shockwaves Induces Muscle Regeneration After Muscle Injury in a Surgical Rat Model. J. Orthop. Res. 2019, 38, $1386-1397$. [CrossRef] [PubMed]

64. Langendorf, E.K.; Klein, A.; Rommens, P.M.; Drees, P.; Ritz, U.; Mattyasovszky, S.G. Calf Blood Compound (CFC) and Homeopathic Drug Induce Differentiation of Primary Human Skeletal Muscle Cells. Endoscopy 2019, 40, 803-809. [CrossRef] [PubMed]

65. Mattyasovszky, S.G.; Langendorf, E.K.; Ritz, U.; Schmitz, C.; Schmidtmann, I.; Nowak, T.E.; Wagner, D.; Hofmann, A.; Rommens, P.M.; Drees, P. Exposure to Radial Extracorporeal Shock Waves Modulates Viability and Gene Expression of Human Skeletal Muscle Cells: A Controlled in Vitro Study. J. Orthop. Surg. Res. 2018, 13, 75. [CrossRef] [PubMed]

66. Brendel, C.; Mueller-Kuller, U.; Schultze-Strasser, S.; Stein, S.; Chen-Wichmann, L.; Krattenmacher, A.; Kunkel, H.; Dillmann, A.; Antoniou, M.N.; Grez, M. Physiological Regulation of Transgene Expression by a Lentiviral Vector Containing the A2UCOE Linked to a Myeloid Promoter. Gene Ther. 2011, 19, 1018-1029. [CrossRef] [PubMed] 